\title{
Electronic Properties of Ti Sites in Ziegler-Natta Catalysts
}

\author{
Alessandro Piovano, Matteo Signorile, Luca Braglia, Piero Torelli, Andrea Martini, Toru Wada, \\ Gentoku Takasao, Toshiaki Taniike, and Elena Groppo*
}

Cite This: ACS Catal. 2021, 11, 9949-9961

Read Online

\section{ACCESS | L Illl Metrics \& More | 回 Article Recommendations | (1) Supporting Information}

ABSTRACT: Although Ziegler-Natta $(\mathrm{ZN})$ catalysts play a major role in the polyolefin market, a true understanding of their properties at the molecular level is still missing. In particular, there is a lack of knowledge on the electronic properties of Ti sites. Theoretical calculations predict that the electron density of the Ti sites in the precatalysts correlates with the activation energy for olefin insertion in the Ti-alkyl bond generated at these sites after activation by Al-alkyls. It is also well known that the effective charge on the Ti sites in the activated catalysts affects the olefin $\pi$ complexation. In this contribution, we exploit two electronic spectroscopies, UV-vis and $\mathrm{Ti} \mathrm{L}_{2,3}$-edge near-edge $\mathrm{X}$-ray absorption fine structure (NEXAFS), complemented with theoretical simulation to investigate three $\mathrm{ZN}$ precatalysts of increasing complexity (up to an industrial system) and the corresponding catalysts activated by triethylaluminum (TEAl). We provide compelling evidence for the presence of monomeric 6 -fold-coordinated $\mathrm{Ti}^{4+}$ species in all of the precatalysts,

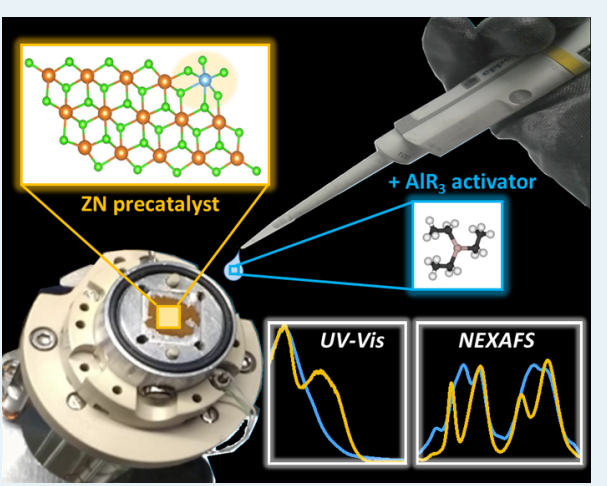
which however differ in the effective charge on the Ti sites. We also unambiguously demonstrate that these sites are reduced by TEAl to two types of monomeric 5-coordinated $\mathrm{Ti}^{3+}$, either alkylated or not, and that the former are involved in ethylene polymerization. In addition, small $\mathrm{TiCl}_{3}$ clusters are formed in the industrial catalyst, likely due to the occurrence of severe reducing conditions within the catalyst pores. These data prove the potential of these two techniques, coupled with simulation, in providing an accurate description of the electronic properties of heterogeneous $\mathrm{ZN}$ catalysts.

KEYWORDS: Ziegler-Natta, Ti, NEXAFS, catalysts, electronic properties, UV-vis

\section{INTRODUCTION}

Ziegler-Natta $(\mathrm{ZN})$ catalysts are at the heart of the polyolefin production, affording at present almost 80 million tons of polypropylene per year, with a worldwide economic turnover exceeding 100 billion dollars, ${ }^{1}$ and their great properties are recognized as a fundamental benchmark for the whole chemical industry. Their extraordinary success in terms of activity and selectivity is due to the perfect combination of four indispensable components, namely, a titanium chloride precursor, a high surface area $\mathrm{MgCl}_{2}$ support, organic molecules acting as Lewis bases (namely, the electron donors), and an aluminum alkyl activator. ${ }^{2-5}$ The first three components constitute the precatalyst, which can be prepared following different routes that have been optimized in decades of industrial research ${ }^{6,7}$ to generate multigrain and porous spherical particles as a result of aggregation of so-called primary particles. ${ }^{8-14}$ This hierarchical structure is fundamental to guarantee controlled fragmentation during olefin polymerization and to provide a polymer with the desired morphology.

It is widely accepted that the primary particles are nanosized and disordered $\mathrm{MgCl}_{2}$ plates (usually called $\delta-\mathrm{MgCl}_{2}$ ) whose surfaces are capped by $\mathrm{TiCl}_{4}$ and electron-donor molecules. ${ }^{15}$ Following the mechanical route, $\mathrm{MgCl}_{2}$ and the electron donor are ball-milled together and post-treated with $\mathrm{TiCl}_{4}$ : the longer the grinding time, the higher the surface area and the defectivity of the $\delta$ - $\mathrm{MgCl}_{2}$ primary particles, which are both beneficial for the development of the catalyst activity. ${ }^{16-22}$ When the precatalysts are prepared with modern chemical routes, for example, through the precipitation of a $\mathrm{MgCl}_{2}$ solution $^{23-26}$ or through the solid-state conversion of $\mathrm{Mg}$ $(\mathrm{OR})_{2}$ precursors in the presence of $\mathrm{TiCl}_{4}$ and the electron donors, ${ }^{26-30}$ the size of the $\delta-\mathrm{MgCl}_{2}$ primary particles decreases by one order of magnitude and their structural disorder increases, with a concomitant increase of the catalyst performance. Besides affecting the size and the disorder of the $\delta-\mathrm{MgCl}_{2}$ primary particles, the synthesis protocol strongly affects their morphology, i.e., the relative extension of different surfaces. In our recent work, ${ }^{31,32}$ we demonstrated that the mechanical ball-milling of $\mathrm{MgCl}_{2}$ favors the formation of surfaces exposing strongly acidic $\mathrm{Mg}^{2+}$ sites (i.e., the (110), (012) and (015) ones) at the expenses of the basal (001) one

Received: April 16, 2021

Revised: July 8, 2021

Published: July 26, 2021

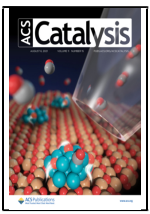


and that the relative contribution of the (110) surface to the overall $\mathrm{MgCl}_{2}$ morphology is even greater for the chemically activated $\mathrm{ZN}$ catalysts.

Since the structure and the morphology of the $\delta-\mathrm{MgCl}_{2}$ primary particles are retained during the catalyst formation in the presence of an aluminum alkyl activator, the synthetic protocol ultimately drives the distribution of the active sites and their stereospecificity. ${ }^{33-41}$ Albeit this concept is widely accepted based on the analysis of the polymer produced, so far direct experimental evidence on the different properties of the $\mathrm{Ti}$ sites in $\mathrm{ZN}$ catalysts has been largely restricted. The majority of experimental data on $\mathrm{ZN}$ catalysts refer to the precatalysts or to aged catalysts, and usually provide information on either $\mathrm{MgCl}_{2}$ or the electron donors, while the properties of the $\mathrm{Ti}$ sites are only indirectly extrapolated. One of the main aspects missing from the state-of-the-art technology in $\mathrm{ZN}$ catalysis is an understanding of the electronic features of the $\mathrm{Ti}$ sites, which in turn strongly influences the monomer insertion process. Indeed, more electron-deficient $\mathrm{Ti}$ active species are known to enhance both the olefin $\pi$-complexation and the agostic interaction within the $\alpha$-agostic-assisted Cossee-Arlman mechanism. ${ }^{42}$ However, a few recent computational studies indicate that the charge state of the Ti sites in $\mathrm{ZN}$ precatalysts is sensitive to the coordination environment and correlates with the activation energy of ethylene insertion into the Ti-alkyl bond. ${ }^{43,44} \mathrm{~A}$ critical deficiency of experimental data mainly arises from some intrinsic difficulties, which make the active sites elusive to most of the experimental techniques. Among all, a small fraction of the $\mathrm{Ti}$ sites (a few wt \%) and their heterogeneity (i.e., copresence of active, poorly active/dormant, and inactive sites) are the most relevant ones. ${ }^{45}$

Herein, we provide an unprecedented contribution in the field by thoroughly investigating the electronic properties of the $\mathrm{Ti}$ sites in three $\mathrm{ZN}$ precatalysts synthesized according to different protocols (whereby $\delta-\mathrm{MgCl}_{2}$ is obtained either by mechanical or chemical routes), and in the three related catalysts activated by triethyl aluminum (TEAl), before and after ethylene polymerization, by coupling diffuse reflectance (DR) UV-vis and $\mathrm{Ti}_{2,3}$-edge near-edge X-ray absorption fine structure (NEXAFS) spectroscopy, complemented by theoretical simulations. Both techniques provide information on the electronic structure of the Ti sites, which in turn allow going back to their geometrical structure at the atomic scale. In more detail, absorptions in the UV-vis range are due to the transfer of electrons from molecular orbitals (MO) mainly centered on the ligand to molecular orbitals mainly centered on $\mathrm{Ti}$ [chargetransfer (CT) transitions], and/or to the transfer of electrons between filled and empty $\mathrm{d}$ orbitals in $\mathrm{Ti}(\mathrm{d}-\mathrm{d}$ transitions), the latter being possible only for reduced $\mathrm{Ti}$ species. ${ }^{45}$ On the other hand, $\mathrm{Ti} \mathrm{L}_{2,3}$-edge NEXAFS spectra originate from $\operatorname{Ti}(2 \mathrm{p}) \rightarrow \operatorname{Ti}(3 \mathrm{~d})$ electronic transitions and act as a probe of the density of unoccupied valence states. Hence, both techniques are in principle very sensitive to the Ti-ligand interactions and able to discriminate between sites having a similar geometrical environment but yet a different electronic affinity toward the monomer. Nevertheless, DR UV-vis spectroscopy has been only rarely used for investigating $\mathrm{ZN}$ catalysts, ${ }^{45,46}$ and often the spectra were not sufficiently (or properly) interpreted. In the last decade, some of the authors systematically exploited DR UV-vis spectroscopy to investigate a series of ZN (pre)catalysts and related systems, ${ }^{47-52}$ never reaching, however, such a high level of details as in the present work, which benefits the complementarity with NEXAFS spectroscopy and density-functional theory (DFT) calculation. As far as NEXAFS (in the soft X-ray range) is concerned, the short attenuation length of soft X-rays has long prevented the application of NEXAFS in reaction conditions, and in situ observations of surface reactions were limited only in the presence of gases with pressures lower than $10^{-6}$ Torr. Recently, new experimental setups have been developed to go beyond this limitation, and a few examples of operando NEXAFS investigations of heterogeneous catalysts can be found in the literature. ${ }^{53-62}$ Most of them are related to the study of metal oxides or supported metal nanoparticles, while to the best of our knowledge there are yet no examples of NEXAFS applied to ZN catalysts.

\section{EXPERIMENTAL SECTION}

2.1. Samples. 2.1.1. Synthesis of Precatalysts. A ballmilled $\mathrm{MgCl}_{2}$ sample (hereafter pristine $\mathrm{MgCl}_{2}$ ) was donated by Toho Titanium Co., Ltd., with a specific surface area (SSA) of $9.3 \mathrm{~m}^{2} \mathrm{~g}^{-1}$, as determined by $\mathrm{N}_{2}$ adsorption measurements. Twenty-five grams of it was filled in a $0.5 \mathrm{~L}$ stainless steel pot with 235 stainless steel balls (10 $\mathrm{mm}$ diameter) and subjected to planetary ball milling. The milling time was adjusted to make SSA about 8 times higher, resulting in an SSA of $73 \mathrm{~m}^{2}$ $\mathrm{g}^{-1}$. The $\mathrm{MgCl}_{2} / \mathrm{TiCl}_{4}$ precatalyst was prepared by titanation of the so-obtained high surface area $\mathrm{MgCl}_{2}$ in the presence of $\mathrm{TiCl}_{4}$ vapors at $80{ }^{\circ} \mathrm{C}$, followed by degassing at the same temperature in high vacuum, resulting in a final titanium loading close to $1.0 \mathrm{wt} \%$ with respect to $\mathrm{MgCl}_{2}$.

The same pristine $\mathrm{MgCl}_{2}$ was also ball-milled (for the same milling time) in the presence of ethylbenzoate (hereafter $\mathrm{EB}$ ) as an electron donor at a $\mathrm{MgCl}_{2} / \mathrm{EB}$ molar ratio of $16: 1$. The so-obtained $\mathrm{MgCl}_{2} / \mathrm{EB}$ sample was reacted in heptane with $\mathrm{TiCl}_{4}$ at $90{ }^{\circ} \mathrm{C}$ for $2 \mathrm{~h}$, washed several times with fresh heptane, and finally, dried under vacuum at $90{ }^{\circ} \mathrm{C}$. The resulting $\mathrm{MgCl}_{2} / \mathrm{EB} / \mathrm{TiCl}_{4}$ precatalyst has the final $\mathrm{Ti}$ and $\mathrm{EB}$ contents of 1.0 and $6.3 \mathrm{wt} \%$, respectively.

The chemically activated $\mathrm{ZN}$ precatalyst, $\mathrm{ZNC}(\mathrm{DBP})$, was prepared starting from $\mathrm{Mg}(\mathrm{OEt})_{2}$ according to a patent ${ }^{63}$ with slight modifications, ${ }^{28,29,39}$ where $n$-dibutyl phthalate (hereafter DBP) was used as an internal electron donor. The Ti and DBP contents were determined to be 2.6 and 14.1 wt \%, respectively.

All of the samples were stored and transferred thoroughly under an inert atmosphere to avoid contamination by moisture.

2.1.2. Activation of Precatalysts. The activation of the precatalysts was accomplished at room temperature by impregnating the powders with a diluted solution of triethyl aluminum (TEAl) (10 v/v \% in hexane), attaining an average $\mathrm{Al} / \mathrm{Ti}$ stoichiometry of $2: 1$. The impregnation was performed in the glovebox, directly inside the measurement cells, and the solvent was successively removed by degassing in a high vacuum (DR UV-vis) or by flowing the cell with $\mathrm{He}$ (NEXAFS).

2.2. Experimental Methods. DR UV-vis spectra were measured with a Varian Cary5000 spectrophotometer, equipped with a diffuse reflectance sphere. The samples were measured in powder form, in a homemade cell with a window in optical quartz (suprasil), which allows performing treatments in a vacuum and/or in the presence of gases. The spectra were collected in a reflectance mode and successively converted as Kubelka-Munk F(R) function. 
Ti $\mathrm{L}_{2,3}$-edge NEXAFS spectra were collected at the APE-HE beamline of the Elettra Sincrotrone Trieste facility in total electron yield (TEY) mode, which renders the measure highly surface sensitive (the probing depth being typically of a few $\mathrm{nm}$ ). An ambient-pressure NEXAFS cell was adopted, ${ }^{64}$ allowing to perform measurements in the presence of gases. The samples, in powder form, were pressed inside a thin indium plate and fixed inside the cell. All the procedures were done inside a $\mathrm{N}_{2}$-filled glove box to prevent contamination. The cell was then inserted inside the ultrahigh vacuum chamber of the APE-HE beamline and connected to a gas line. All of the measurements were performed under a $5 \mathrm{~mL} \mathrm{~min}{ }^{-1}$ He flow at 1 bar. A liquid nitrogen trap was employed to remove adventitious water contaminations from the gas line. Ethylene polymerization was performed upon dosing small ethylene pulses inside the He flow. The spectra were collected with an energy step of $0.1 \mathrm{eV}$ and an integration time per step of $0.18 \mathrm{~s}$. The so collected data were processed using THORONDOR software ${ }^{65}$ to calibrate the energy of the spectra (with reference to the $1 \mathrm{~s} \rightarrow \pi^{*}$ transition at $399.8 \mathrm{eV}$ of nitrogen, present as $\mathrm{Si}_{3} \mathrm{~N}_{4}$ in the membrane of the cell), ${ }^{66}$ subtract the anomalous background produced by the interaction of soft X-rays with all of the crossed media (i.e., the $\mathrm{Si}_{3} \mathrm{~N}_{4}$ membrane with a thickness of $100 \mathrm{~nm},{ }^{64}$ and a thickness of $500 \mu \mathrm{m}$ of $\mathrm{He}$ gas at $1 \mathrm{bar}$ ), flatten the baseline of the spectra, and normalize them to the intensity of the most intense feature of the $\mathrm{Ti}_{3}$-edge.

2.3. Simulation of the $\mathrm{UV}-\mathrm{vis}$ and $\mathrm{Ti} \mathrm{L}_{2,3}$-Edge NEXAFS Spectra. The UV-vis and $\mathrm{Ti} \mathrm{L}_{2,3}$-edge NEXAFS spectra of the precatalysts were simulated using the ORCA (v 4.2.1) code $^{67}$ adopting as structural models some of the nanoclusters proposed by Takasao et al. ${ }^{68}$ In detail, the most stable $15 \mathrm{MgCl}_{2} / 4 \mathrm{TiCl}_{4}$ models they proposed (Figure $7 \mathrm{~b}, \mathrm{c}$ in ref 68) were simplified by selectively removing $\mathrm{TiCl}_{x}$ units. The simplified nanoclusters were reoptimized using DFT at the B3LYP level of theory, ${ }^{69,70}$ using the def2-TZVP as the basis set. ${ }^{71}$ Four models were considered, as shown in Figure 1: (i) a $\mathrm{Ti}$ cation 6-fold-coordinated on the $\mathrm{MgCl}_{2}(110)$ surface, which is so far considered the most representative picture for the Ti sites in $\mathrm{ZN}$ catalysts (hereafter referred to as hexa-1); (ii) two 6-fold-coordinated $\mathrm{Ti}$ species in close

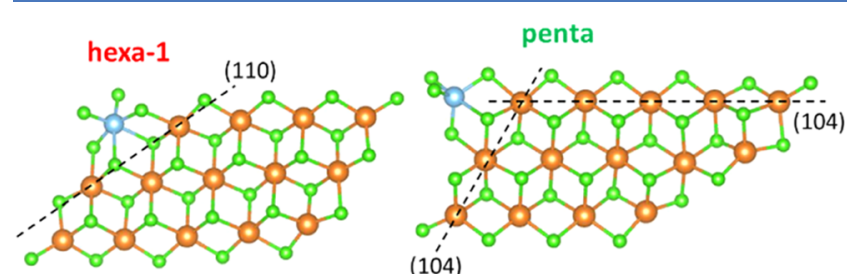

(104)
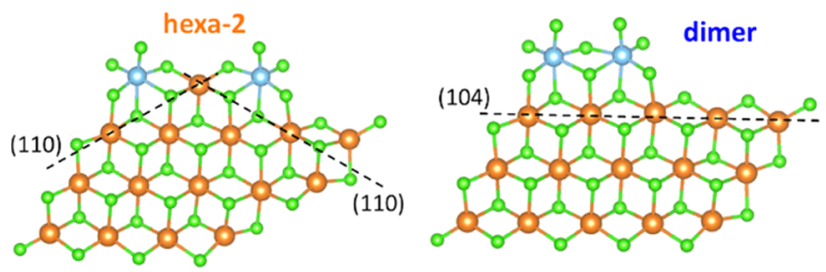

Figure 1. Four models representative of different types of $\mathrm{TiCl}_{x}$ species on $\mathrm{MgCl}_{2}$ clusters ( $\mathrm{Mg}$ atoms in orange, $\mathrm{Cl}$ atoms in green, and $\mathrm{Ti}$ atoms in light blue). The models were selectively cut from the machine learning-aided structures of $\mathrm{TiCl}_{4}$-capped $\mathrm{MgCl}_{2}$ nanoplates determined by Takasao et al. ${ }^{68}$ Dashed lines indicate the $\mathrm{MgCl}_{2}$ surfaces involved in $\mathrm{TiCl}_{x}$ chemisorption. proximity to two intersecting $\mathrm{MgCl}_{2}(110)$ surfaces (hereafter hexa-2); (iii) a 5-fold-coordinated $\mathrm{Ti}$ cation at a corner generated by the intersection of two $\mathrm{MgCl}_{2}(104)$ surfaces (hereafter penta); and (iv) a $\mathrm{Ti}_{2} \mathrm{Cl}_{2 x}$ dimer on a $\mathrm{MgCl}_{2}(104)$ surface (hereafter dimer), which in the past was considered responsible for the stereoselective propylene polymerization, ${ }^{72}$ even though, more recently, its relevance has been questioned. $^{83-78}$ The atomic coordinates of the four models are provided in the Supporting Information (SI).

The hexa- 1 model in Figure 1 was used as a starting point for building up five models representative for the possible $\mathrm{Ti}$ species formed upon reaction with a TEAl activator, according to the most common activation paths proposed in the literature, ${ }^{2,5}$ which include the formation of a coordination vacancy on the $\mathrm{Ti}$ site through the homolytic or heterolytic cleavage of a $\mathrm{Cl}$ ligand (dechlorination) and the exchange of another $\mathrm{Cl}$ ligand with an ethyl group (transalkylation or metathesis). The five structurally optimized models (whose atomic coordinates are provided in the SI) are represented in Figure $\mathrm{S} 1$ and are referred hereafter as (i) $\mathrm{Ti}^{\mathrm{IV}} \mathrm{Cl}_{5}{ }^{\oplus}$, obtained from the heterolytic cleavage of a $\mathrm{Cl}$ ligand; (ii) $\mathrm{Ti}^{\mathrm{III}} \mathrm{Cl}_{5}$, derived from the homolytic cleavage of a $\mathrm{Cl}$; (iii) $\mathrm{Ti}^{\mathrm{IV}} \mathrm{Cl}_{5} \mathrm{R}$, resulting from transalkylation; (iv) $\mathrm{Ti}^{\mathrm{IV}} \mathrm{Cl}_{4} \mathrm{R}^{\oplus}$, obtained through transalkylation of model $\mathrm{Ti}^{\mathrm{IV}} \mathrm{Cl}_{5}{ }^{\oplus}$; and $(\mathrm{v}) \mathrm{Ti}^{\mathrm{III}} \mathrm{Cl}_{4} \mathrm{R}$, obtained by transalkylation of model $\mathrm{Ti}^{\mathrm{III}} \mathrm{Cl}_{5}$.

For each one of the optimized models described above, the $\mathrm{UV}$-vis spectra and $\mathrm{L}_{2,3}$-edge NEXAFS spectra were simulated to single out their spectroscopic fingerprints and to understand the sensitivity of the two techniques to small variations in the structure of the Ti sites. It is important to notice that none of the models, alone, can reproduce the complexity of the $\mathrm{ZN}$ (pre)catalysts, indicating that the real catalyst is not as simple as the models. Meanwhile, some models capture features of the experimental spectra more than the others, and hence, comparison between simulated and experimental spectra can allow discriminating between highly probable and lessprobable structures. The UV-vis spectra were simulated through the simplified Tamm-Dancoff formalism proposed by Grimme. $^{79}$ States up to $10 \mathrm{eV}$ were considered in the calculations; all other parameters were set to the ORCA defaults. $\mathrm{L}_{2,3}$-edge NEXAFS spectra were computed with the DFT/ROCIS method. ${ }^{80}$ Since the L-edge transitions involve core electrons, during the NEXAFS spectra simulation, relativistic corrections have been included through the ZORA formalism. ${ }^{81}$ The orbitals involved in the $\mathrm{Ti} \mathrm{L}_{2,3}$ transitions were manually selected, including the $\mathrm{Ti} 2 \mathrm{p}$ as donor orbitals and the 100 lower energy unoccupied orbitals as acceptor ones; 100 transitions were calculated per spin state. The spin-orbit coupling correction was included in the calculations. The energy scale for simulated NEXAFS spectra has been calibrated for an improved comparison with experimental data by a multiplicative scaling factor (1.022). The latter has been obtained by comparing the simulated spectrum of $\mathrm{TiCl}_{4}$ with the experimental one available from the literature. $^{82}$

\section{RESULTS AND DISCUSSION}

3.1. Electronic Properties of the $\mathrm{Ti}^{4+}$ Sites in the Precatalysts. Figure 2 a shows the DR UV-vis spectra of the three precatalysts, after normalization of the intensity to the most intense band for a better comparison. ${ }^{83}$ The three spectra mostly reflect the electronic fingerprints of the $\mathrm{TiCl}_{x}$ species since bare $\mathrm{MgCl}_{2}$ has no absorption in the whole UV-vis 

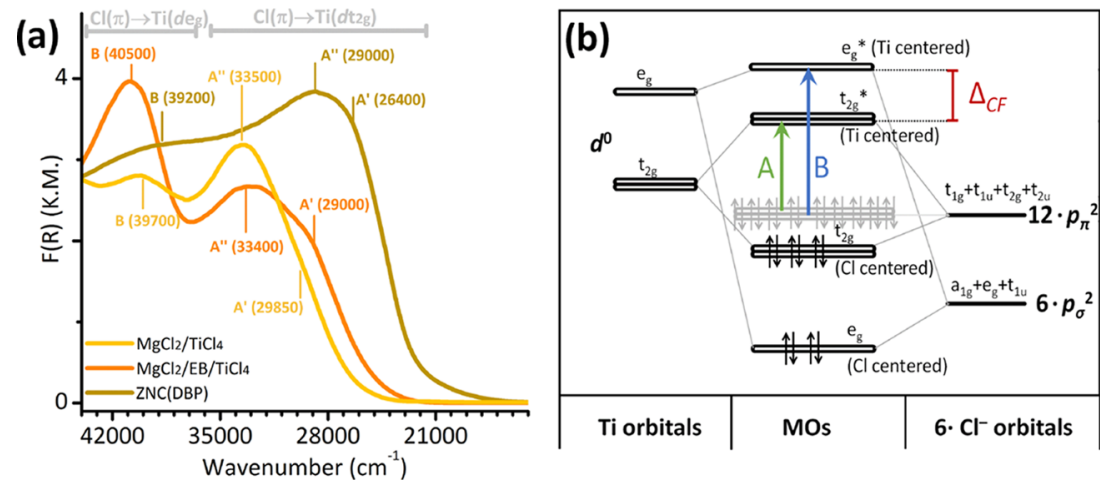

Figure 2. (a) DR UV-vis spectra of the three precatalysts. The position of the maxima of the absorption bands (evaluated at the minima of the second derivatives) is also indicated, as well as the main assignments. (b) Simplified molecular orbital diagram for a $\mathrm{Ti}^{4+}$ metal center in an octahedral field surrounded by six $\sigma$-bonded $\mathrm{Cl}^{-}$ligands, with a $\pi$-donor nature. The ligand-to-metal charge-transfer transitions observed by $\mathrm{DR}$ UV-vis spectroscopy are also reported (arrows A and B). A more rigorous MO diagram is shown in Figure S3.

Table 1. Experimentally Observed Bands in the DR UV-vis and Ti $\mathrm{L}_{2,3}$ Edge NEXAFS Spectra of the Three Precatalysts and Their Assignment ${ }^{a}$

\begin{tabular}{|c|c|c|c|c|c|c|}
\hline technique & band label & assignment & units & $\mathrm{MgCl}_{2} / \mathrm{TiCl}_{4}$ & $\mathrm{MgCl}_{2} / \mathrm{EB} / \mathrm{TiCl}_{4}$ & $\mathrm{ZNC}(\mathrm{DBP})$ \\
\hline \multirow[t]{5}{*}{ UV-vis } & $\mathrm{A}^{\prime}$ & $\mathrm{Cl}(\pi) \rightarrow \mathrm{Ti}\left(\mathrm{dt}_{2 \mathrm{~g}}\right)$ & $\mathrm{cm}^{-1}$ & 29850 & 29000 & 26400 \\
\hline & $\mathrm{A}^{\prime \prime}$ & $\mathrm{Cl}(\pi) \rightarrow \operatorname{Ti}\left(\mathrm{dt}_{2 \mathrm{~g}}\right)$ & $\mathrm{cm}^{-1}$ & 33500 & 33400 & 29000 \\
\hline & B & $\mathrm{Cl}(\pi) \rightarrow \operatorname{Ti}\left(\mathrm{d}_{\mathrm{eg}}\right)^{\circ}$ & $\mathrm{cm}^{-1}$ & 39700 & 40500 & 39200 \\
\hline & & $\Delta_{\mathrm{CF}}(\mathrm{UV})$ & $\mathrm{cm}^{-1}$ & 8025 & 9300 & 11500 \\
\hline & & & $\mathrm{eV}$ & 0.99 & 1.15 & 1.43 \\
\hline \multirow[t]{4}{*}{ NEXAFS } & a & $\operatorname{Ti}(\mathrm{p}) \rightarrow \operatorname{Ti}\left(\mathrm{dt}_{2 \mathrm{~g}}\right)$ & $\mathrm{eV}$ & 458.26 & 458.26 & 458.26 \\
\hline & b1 & $\operatorname{Ti}(\mathrm{p}) \rightarrow \operatorname{Ti}\left(\mathrm{d}_{\mathrm{eg}}\right)$ & $\mathrm{eV}$ & 459.86 & 459.79 & 460.02 \\
\hline & b2 & $\operatorname{Ti}(\mathrm{p}) \rightarrow \operatorname{Ti}\left(\mathrm{d}_{\mathrm{eg}}\right)$ & $\mathrm{eV}$ & 460.52 & 460.62 & 460.50 \\
\hline & & $\Delta_{\mathrm{CF}}(\mathrm{NEXAFS})$ & $\mathrm{eV}$ & 1.93 & 1.94 & 2.00 \\
\hline
\end{tabular}

${ }^{a_{T}}$ The values of the crystal-field splitting, $\Delta_{\mathrm{CF}}$, are also reported, where $\Delta_{\mathrm{CF}}(\mathrm{UV})=E(\mathrm{~B})-\left[E\left(\mathrm{~A}^{\prime}\right)+E\left(\mathrm{~A}^{\prime \prime}\right)\right] / 2$ and $\Delta_{\mathrm{CF}}(\mathrm{NEXAFS})=[E(\mathrm{~b} 1)+$ $E(\mathrm{~b} 2)] / 2-E(\mathrm{a})$.

region and the contribution of the electron donors is negligible (Figure S2). The spectra are very different from each other, implying that the electronic properties of the $\mathrm{Ti}$ sites in the precatalysts are not the same, despite the fact that the $\mathrm{Ti}^{4+}$ sites are expected to have the same formal oxidation state $(+4)$, similar coordination (6-fold-coordinated), and should be surrounded mainly by chlorine ligands in all of the cases.

Since $\mathrm{Ti}^{4+}$ has a $\mathrm{d}^{0}$ electronic configuration, in the DR UVvis spectra, we observe essentially the electron transfer between the filled $\pi$ levels of $\mathrm{Cl}$ and the vacant $\mathrm{d}$ orbitals of $\mathrm{Ti}$, which are split because of the crystal field effect. In the simple assumption of octahedral coordination, the $\mathrm{d}$ orbitals of $\mathrm{Ti}$ are split into $\mathrm{dt}_{2 \mathrm{~g}}$ and $\mathrm{de}_{\mathrm{g}}$ levels, separated by the crystal-field splitting $\left(\Delta_{\mathrm{CF}}=10 \Delta q\right)$. Figure $2 \mathrm{~b}$ represents a simplified molecular orbital (MO) diagram for a $\mathrm{Ti}^{4+}$ surrounded by six chlorine ligands in an octahedral field, taking into account that chlorine, as all of the halides, is a $\pi$-donor ligand. ${ }^{84,85}$ A more rigorous MO diagram is displayed in Figure S3. The chargetransfer (CT) transitions observed by DR UV-vis spectroscopy are also reported (arrows A and B in Figure 2b). Twelve $\mathrm{p}$ orbitals (two for each chlorine ligand) are available for $\pi$ bonding with the $\mathrm{d}$ orbitals of $\mathrm{Ti}^{4+}$, which combine with each other to give symmetry-adapted linear combination (SALC) orbitals of different symmetry. Only the $t_{2 g}$ set has any significant impact on the MO diagram since they mix with the $\mathrm{Ti}^{4+} \mathrm{d}$ orbitals of the same symmetry $\left(\mathrm{d}_{x y}, \mathrm{~d}_{x z}, \mathrm{~d}_{y z}\right) .{ }^{84}$ For $\pi$ donor ligands, $\pi$-SALCs have lower energy than the metal atomic orbitals. Hence, the bonding MOs of $t_{2 g}$ symmetry are ligand-centered and are filled, while the antibonding $t_{2 \mathrm{~g}} * \pi$ -
MOs are metal-centered. ${ }^{85}$ This effectively raises the metal $\mathrm{dt}_{2 \mathrm{~g}}$ atomic orbitals and decreases the magnitude of $\Delta_{\mathrm{CF}}$ with respect to the $\sigma$-bonded case. According to this scheme, the lowest energy electronic absorptions are due to transitions of the type $\mathrm{Cl}(\pi) \rightarrow \operatorname{Ti}\left(\mathrm{dt}_{2 \mathrm{~g}}\right)$ (transition $\mathrm{A}$ in Figure $2 \mathrm{~b}$ and bands $\mathrm{A}^{\prime}$ and $\mathrm{A}^{\prime \prime}$ in Figure $\left.2 \mathrm{a}\right)$ and $\mathrm{Cl}(\pi) \rightarrow \mathrm{Ti}(\mathrm{deg})$ (transition $B$ in Figure $2 b$ and bands $B$ in Figure 2a), respectively. ${ }^{86}$ The experimental spectra are not constituted simply by two bands $\left(\pi \rightarrow \mathrm{dt}_{2 \mathrm{~g}}\right.$ and $\left.\pi \rightarrow \mathrm{de}_{\mathrm{g}}\right)$ separated by $10 \Delta q$ because the Cl-centered molecular orbitals are not perfectly equivalent as displayed in Figure $2 \mathrm{~b}$ for simplicity; ${ }^{84}$ this causes the splitting of the $\mathrm{Cl}(\pi) \rightarrow \mathrm{Ti}\left(\mathrm{dt}_{2 \mathrm{~g}}\right)$ transition into bands $\mathrm{A}^{\prime}$ and $\mathrm{A}^{\prime \prime}$ in Figure $2 \mathrm{a}$. The same splitting is not observed for the $\mathrm{Cl}(\pi) \rightarrow \operatorname{Ti}\left(\mathrm{d}_{\mathrm{eg}}\right)$ bands because the second component falls at higher wavenumbers, out of the measurement range.

The spectra of $\mathrm{Ti}^{4+}$ hexahalides reported in the literature are characterized by large variability in the position and in the relative intensity of the abovementioned bands, especially when the spectra of compounds in the solid state are compared with those of the $\left[\mathrm{TiCl}_{6}\right]^{2-}$ species in solution. ${ }^{87}$ As an example, the transmission spectrum of $\left[\mathrm{TiCl}_{6}\right]^{2-}$ in acetonitrile displays the $\mathrm{Cl}(\pi) \rightarrow \mathrm{Ti}\left(\mathrm{dt}_{2 \mathrm{~g}}\right)$ transitions in the $29000-$ $31850 \mathrm{~cm}^{-1}$ range and the $\mathrm{Cl}(\pi) \rightarrow \mathrm{Ti}(\mathrm{deg})$ bands in the $38500-42500 \mathrm{~cm}^{-1}$ range, while the reflectance spectrum of solid $\mathrm{K}_{2} \mathrm{TiCl}_{6}$ shows both transitions at much lower energy, in the 23000-30000 and 34500-37800 $\mathrm{cm}^{-1}$ intervals, respectively. The differences have been ascribed to structural variations induced by the packing of the cations in the solid 
state, which results in a distortion of the anion distribution (i.e., changes in angles and bond lengths). ${ }^{87}$

Similar differences characterize the spectra of the three precatalysts reported in Figure 2a. The position of the bands observed in the DR UV-vis spectra (evaluated as the minima in the second derivative curves) are also indicated in Figure $2 \mathrm{a}$ and summarized in Table 1 . The spectrum of $\mathrm{MgCl}_{2} / \mathrm{TiCl}_{4}$ shows the first $\mathrm{Cl}(\pi) \rightarrow \mathrm{Ti}\left(\mathrm{dt}_{2 \mathrm{~g}}\right)$ transition at the highest energy (band $A^{\prime}, 29850 \mathrm{~cm}^{-1}$ ) but also the smallest crystalfield splitting $\Delta_{\mathrm{CF}}(\mathrm{UV})\left(8025 \mathrm{~cm}^{-1}=0.99 \mathrm{eV}\right)$, where $\Delta_{\mathrm{CF}}(\mathrm{UV})$ was evaluated as $\Delta_{\mathrm{CF}}(\mathrm{UV})=E(\mathrm{~B})-\left[E\left(\mathrm{~A}^{\prime}\right)+\right.$ $\left.\mathrm{I}\left(\mathrm{A}^{\prime \prime}\right)\right] / 2$, with $E\left(\mathrm{~A}^{\prime}\right), E\left(\mathrm{~A}^{\prime \prime}\right)$, and $E(\mathrm{~B})$ being the energy positions of bands $A^{\prime}, A^{\prime \prime}$, and $B$, respectively. The spectrum of $\mathrm{ZNC}(\mathrm{DBP})$ shows the first $\mathrm{Cl}(\pi) \rightarrow \mathrm{Ti}\left(\mathrm{dt}_{2 \mathrm{~g}}\right)$ transition at the lowest energy (band $\mathrm{A}^{\prime}, 26400 \mathrm{~cm}^{-1}$ ), and the largest $\Delta_{\mathrm{CF}}(\mathrm{UV})\left(11500 \mathrm{~cm}^{-1}=1.43 \mathrm{eV}\right)$. The spectrum of $\mathrm{MgCl}_{2} / \mathrm{EB} / \mathrm{TiCl}_{4}$ has intermediate properties, with the first $\mathrm{Cl}(\pi) \rightarrow \operatorname{Ti}\left(\mathrm{dt}_{2 \mathrm{~g}}\right)$ transition at $29000 \mathrm{~cm}^{-1}$ and $\Delta_{\mathrm{CF}}(\mathrm{UV})=$ $9300 \mathrm{~cm}^{-1}=1.15 \mathrm{eV}$, and a spectrum very similar to that reported in the literature for $\left[\mathrm{TiCl}_{6}\right]^{2-}$ in acetonitrile. Even though the use of UV-vis spectroscopy is well established in the literature for studying heterogeneous Ti-based catalysts (e.g., in Ti-zeolites), ${ }^{60,88-92}$ determining the $\Delta_{\mathrm{CF}}$ values from the position of the charge-transfer bands in the optical spectrum is rather uncommon and, to the best of our knowledge, never applied in the field of ZN catalysts. Usually, $\Delta_{\mathrm{CF}}$ is estimated in a direct way from the energy position of the $\mathrm{d}-\mathrm{d}$ bands only for transition metals having a $\mathrm{d}^{n}$ electronic configuration with $n \neq 0$, such as $\mathrm{Ti}^{3+}$ ( $\mathrm{d}^{1}$ configuration).

The band assignment discussed above, based on LCAO arguments and on the assumption of octahedral coordination for the Ti cations, is fully confirmed by the simulation of the UV-vis spectra for the four models shown in Figure 1, which are reported in Figure S4. Even though only hexa-1 exhibits an almost perfect octahedral symmetry, all of the four simulated spectra are characterized by two main bands in the 28000$42000 \mathrm{~cm}^{-1}$ region, separated by about $7000 \mathrm{~cm}^{-1}(0.87 \mathrm{eV})$, which is compatible with the experimentally determined $\Delta_{\mathrm{CF}}$ values. The position of the $\mathrm{Cl}(\pi) \rightarrow \mathrm{Ti}\left(\mathrm{dt}_{2 \mathrm{~g}}\right)$ band at a lower energy (band A) is the most sensitive to the geometry of the model, spanning from about $31500 \mathrm{~cm}^{-1}$ for penta to about $34000 \mathrm{~cm}^{-1}$ for hexa-1, whereas the $\mathrm{Cl}(\pi) \rightarrow \mathrm{Ti}\left(\mathrm{dt}_{\mathrm{eg}}\right)$ band at higher energy (band B) is almost constant for all of the models at $40000 \mathrm{~cm}^{-1}$. Interestingly, the same behavior is observed in the experimental spectra: band $\mathrm{B}$ is almost at the same position in the three experimental spectra, while band $\mathrm{A}\left(\mathrm{A}^{\prime}+\mathrm{A}^{\prime \prime}\right)$ appears at different energy in the three spectra. This suggests that UV-vis spectroscopy is indeed sensitive to the local structure of the $\mathrm{Ti}$ sites in $\mathrm{ZN}$ precatalysts and that, on average, the three precatalysts differ in the distribution of the active sites. Unfortunately, the simulated spectra (Figure S4) are not largely different from each other, and all are qualitatively compatible with the experimental ones (Figure 2a). This implies that UV-vis spectroscopy cannot alone be used to assess the structure of the $\mathrm{Ti}^{4+}$ sites in the three $\mathrm{ZN}$ precatalysts or to discard less probable ones. We will see in the following, however, that it will become fundamental to reveal certain types of reduced $\mathrm{Ti}^{3+}$ species in $\mathrm{ZN}$ catalysts.

Complementary information can be obtained by analyzing the $\mathrm{Ti} \mathrm{L}_{2,3}$-edge NEXAFS spectra of the three precatalysts, reported in Figure 3a after normalization to the intensity of the first feature (band a). Generally speaking, a Ti $2 p$ NEXAFS spectrum originates from the $2 \mathrm{p}^{6} 3 \mathrm{~d}^{\mathrm{n}} \rightarrow 2 \mathrm{p}^{5} 3 \mathrm{~d}^{\mathrm{n}+1}$ electronic
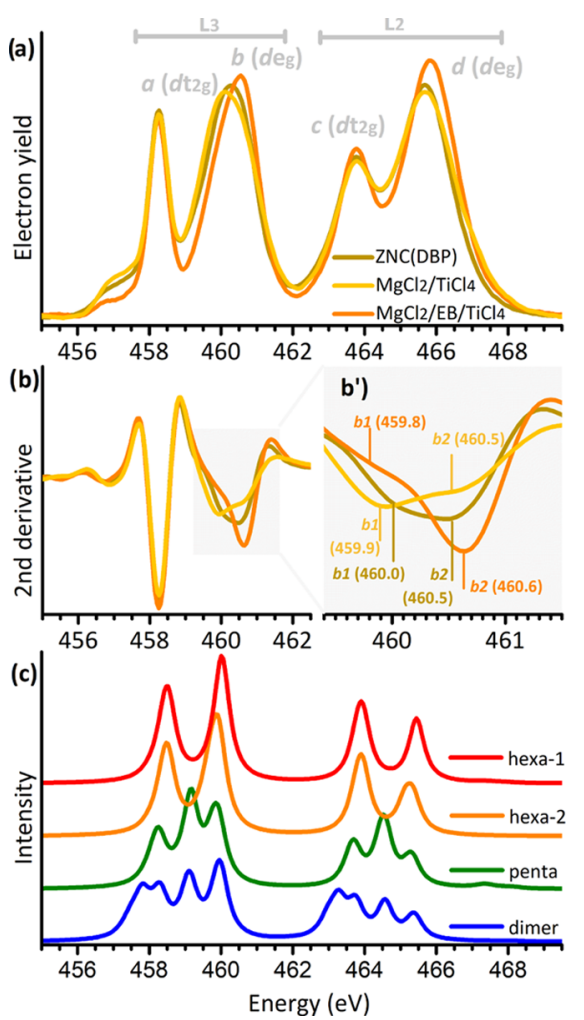

Figure 3. (a) Experimental $\mathrm{Ti}_{2,3}$-edge NEXAFS spectra of the three precatalysts. (b) Second derivatives of the spectra reported in (a) in the $L_{3}$ edge region; $\left(b^{\prime}\right)$ reports a magnification of the second derivative signal for the de $\mathrm{g}_{\mathrm{g}}$ peak in the $\mathrm{L}_{3}$ edge. (c) Simulated $\mathrm{Ti} \mathrm{L}_{2,3^{-}}$ edge NEXAFS spectra of the four models shown in Figure 1 , normalized to the number of the absorbing atoms.

transition. It consists of two sets of bands representing the $\mathrm{L}_{3}$ and $L_{2}$ edges, which correspond to the $2 p_{3 / 2}$ and $2 p_{1 / 2}$ excitations, respectively. Hence, the separation between the $\mathrm{L}_{3}$ and $\mathrm{L}_{2}$ edges is associated with the spin-orbit splitting of the $2 p$ orbitals. For all of the three precatalysts, the separation of the $\mathrm{L}_{3}$ and $\mathrm{L}_{2}$ features is $5.3 \mathrm{eV}$, which is slightly lower than the $\mathrm{L}_{3}-\mathrm{L}_{2}$ splitting observed in the Ti $2 \mathrm{p}$ NEXAFS spectrum of $\mathrm{TiO}_{2}(5.5 \mathrm{eV})^{93-95}$ and $\mathrm{FeTiO}_{3}(5.4 \mathrm{eV}) .^{94}$ Both $\mathrm{L}_{3}$ and $\mathrm{L}_{2}$ edges are split in two main peaks (labeled as a and $b$, and $c$ and $\mathrm{d}$, respectively). Within the molecular orbital picture, this separation is explained as the splitting of the $\mathrm{Ti} 3 \mathrm{~d}$ molecular orbitals dictated by the symmetry of the $\mathrm{Ti}$ species. In the simple picture of a transition metal in octahedral symmetry, the two peaks in both the $\mathrm{L}_{3}$ and $\mathrm{L}_{2}$ edges are then related to electronic transitions to the $\mathrm{dt}_{2 \mathrm{~g}}$ and $\mathrm{de}_{\mathrm{g}}$ orbitals. Therefore, the energy difference between peaks $a$ and $b$ (or $c$ and $d$ ) corresponds to the crystal field splitting $\Delta_{\mathrm{CF}}$ (NEXAFS), which increases in the series $\mathrm{MgCl}_{2} / \mathrm{TiCl}_{4}<\mathrm{MgCl}_{2} / \mathrm{EB} / \mathrm{TiCl}_{4}<$ $\mathrm{ZNC}(\mathrm{DBP})$ in agreement with what was observed in the DRUV-vis spectra, even though the absolute values are higher. This is in agreement with the literature, according to which for $10 \Delta q$ values lower than $3 \mathrm{eV}$ the energy splitting determined by NEXAFS is higher than the real one. ${ }^{94} \mathrm{~A}$ comparison of $\Delta_{\mathrm{CF}}(\mathrm{NEXAFS})$ and $\Delta_{\mathrm{CF}}(\mathrm{UV})$ for the three precatalysts is shown in Figure S5.

Since the $L_{2}$ features are normally broadened compared to the $\mathrm{L}_{3}$ ones because of the shorter lifetime of the $2 \mathrm{p}_{1 / 2}$ corehole, we performed a detailed analysis on the $\mathrm{L}_{3}$ edge only. The energy position of the $\mathrm{dt}_{2 \mathrm{~g}}$ and $\mathrm{de}_{\mathrm{g}}$ peaks (bands $\mathrm{a}$ and $\mathrm{b}$ in 
(a) $\mathrm{MgCl}_{2} / \mathrm{TiCl}_{4}$

(b) $\mathrm{MgCl}_{2} / \mathrm{EB} / \mathrm{TiCl}_{4}$

(c) ZNC(DBP)

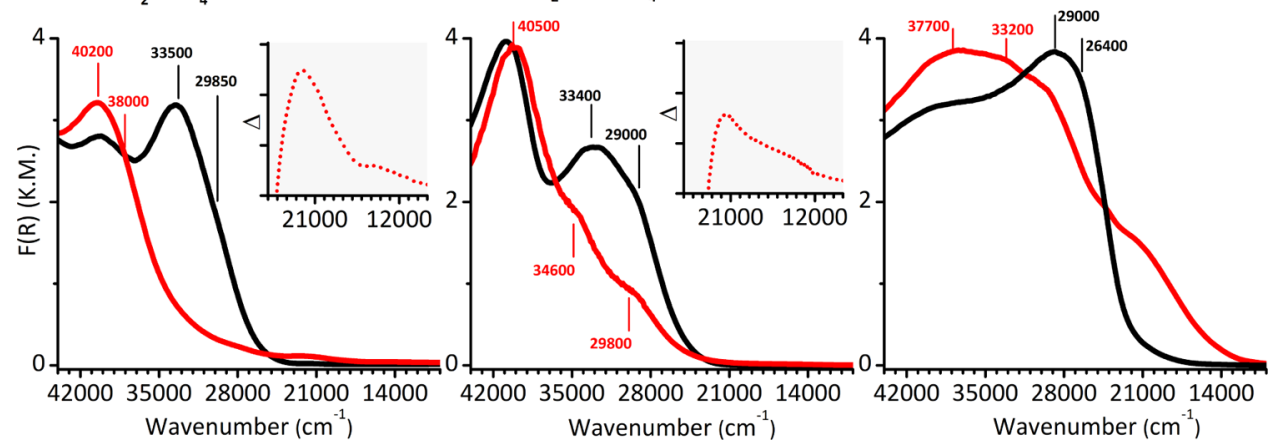

Figure 4. DR UV-vis spectra of the three precatalysts $\left[\mathrm{MgCl}_{2} / \mathrm{TiCl}_{4}, \mathrm{MgCl}_{2} / \mathrm{EB} / \mathrm{TiCl}_{4}\right.$ and $\mathrm{ZNC}(\mathrm{DBP})$, parts (a-c), respectively] before (black) and after interaction with TEAl (red), at an $\mathrm{Al} / \mathrm{Ti}$ ratio of 2:1. The position of the maxima of the absorption bands (evaluated at the minima of the second derivatives) is also indicated, as well as the main assignments. The insets in (a) and (b) report the difference spectra calculated by subtracting the spectrum of the precatalyst from that of the catalyst, magnified in the spectral region dominated by the $d-d$ transition of the $\mathrm{Ti}^{3+}$ species.

Figure 3a) are reported in Table 1 . For all of the three samples, the de $_{\mathrm{g}}$ peak is split into two main components, more evident in the second derivative curves (labeled as peaks b1 and b2 in Figure $\left.3 b^{\prime}\right)$, indicative of at least two main families of $\mathrm{Ti}$ sites. ${ }^{96}$ The larger sensitivity of the de $\mathrm{g}_{\mathrm{g}}$ peak with respect to the $\mathrm{dt}_{2 \mathrm{~g}}$ one can be explained considering that the $\mathrm{de}_{\mathrm{g}}$ orbitals are oriented along the ligand $\sigma$-bonds, thus inducing a larger hybridization of those orbitals with the SALCs centered on the ligands. The origin of the splitting of the de $\mathrm{e}_{\mathrm{g}}$ peak has been investigated by simulating the $\mathrm{Ti} \mathrm{L}_{3,2}$-edge NEXAFS spectra (Figure 3c) of the four $\mathrm{TiCl}_{x}$ models described in Figure 1 . The spectra of the two models containing 6-fold-coordinated $\mathrm{Ti}$ species on the $\mathrm{MgCl}_{2}(110)$ surface (structures hexa-1 and hexa-2) are very similar and well reproduce the experimental ones, with two well-defined $\mathrm{dt}_{2 \mathrm{~g}}$ and $\mathrm{de}_{\mathrm{g}}$ peaks per each L-edge. Interestingly, as already observed from UV-vis spectroscopy, the $\mathrm{dt}_{2 \mathrm{~g}}-\mathrm{de}_{\mathrm{g}}$ split is sensitive even to a small variation in the local structure of the $\mathrm{Ti}$ cations and is slightly smaller for the hexa-2 structure. On the other hand, the simulated spectra of penta and dimer models are much more complex than the experimentally observed ones and are characterized by intense peaks that are not observed in the experimental spectra.

Overall, the thorough analysis of the DR UV-vis and $\mathrm{Ti}_{\mathrm{L}_{3}}$ edge NEXAFS spectra, aided by theoretical simulation, allowed us to conclude that (1) the majority of the Ti sites in the three Ziegler-Natta precatalysts are monomeric 6-fold-coordinated species; (2) in all cases, two main families of $\mathrm{Ti}$ sites characterized by slightly different structural parameters can be identified, whereby the term "family" implies a certain variability within each member of the family; and (3) pentacoordinated $\mathrm{Ti}^{4+}$ cations and dimeric $\mathrm{Ti}^{4+}$ species are very unlikely. It is worth noticing here that the two techniques converge to the same picture, despite the fact that the information depths of UV-vis and TEY NEXAFS are very different (TEY NEXAFS only probes a few nm of the surface of the catalyst, while UV-vis is sensitive to the bulk). Nevertheless, the three precatalysts differ in the average crystal field splitting, $\Delta_{\mathrm{CF}}$. For a specific system in a certain coordination geometry, $\Delta_{\mathrm{CF}}$ depends on both the effective oxidation state of the metal and the nature of the ligands. Upon assuming that the nature of the ligands is roughly the same for the three precatalysts (chlorine anions), the differences in the $\Delta_{\mathrm{CF}}$ values determined by both techniques indicate that the effective oxidation state of the $\mathrm{Ti}$ sites is slightly different in the three cases. With reference to the schematic MO diagram in Figure $2 b$, the higher the effective oxidation state of $\mathrm{Ti}$, the easier the electron transfer from the $\mathrm{Cl}$ ligands. This corresponds to a decrease in the energy of the $\mathrm{dt}_{2 \mathrm{~g}}$ * molecular orbitals, and hence, to an increase in the splitting energy $\Delta_{\mathrm{CF}}$. On this basis, the spectroscopic data reported in Figures 2 and 3 and summarized in Table 1, indicate that, on average, the $\mathrm{Ti}$ sites are slightly more positive in $\mathrm{ZNC}(\mathrm{DBP})$ than in $\mathrm{MgCl}_{2} / \mathrm{EB} / \mathrm{TiCl}_{4}$ and $\mathrm{MgCl}_{2} / \mathrm{TiCl}_{4}$. This result apparently contradicts with previous findings from theoretical calculations, ${ }^{76,97}$ according to which the presence of electron donors nearby the $\mathrm{Ti}$ site should increase the $\mathrm{Ti}$ electron density (and not decrease it) since the ionic nature of the system allows $\mathrm{Ti}$ species to electronically feel the surrounding environment in a remote fashion. Note, however, that in real systems, the $\mathrm{Ti}$ charge reflects various factors besides the presence of donors nearby, such as the $\mathrm{Ti} / \mathrm{Mg}$ ratio, as well as the local surface coverage. ${ }^{43}$ Hence, these data highlight the importance of combining theoretical accounts carried out on model systems with experimental data collected on real systems, which are inevitably more complex.

3.2. Electronic Properties of $\mathrm{Ti}$ Sites in Activated Catalysts. After interaction with $\mathrm{TEAl}(\mathrm{Al} / \mathrm{Ti}=2: 1)$, the $\mathrm{DR}$ $\mathrm{UV}$-vis spectra of the three precatalysts drastically change, as shown in Figure 4. The general behavior is the same in the three cases, although some differences can be pointed out. For $\mathrm{MgCl}_{2} / \mathrm{TiCl}_{4}$ (Figure 4a) and $\mathrm{MgCl}_{2} / \mathrm{EB} / \mathrm{TiCl}_{4}$ (Figure $4 \mathrm{~b}$ ), the intense band ascribed to the $\mathrm{Cl}(\pi) \rightarrow \mathrm{Ti}\left(\mathrm{dt}_{2 \mathrm{~g}}\right)$ chargetransfer transition upward shifts by about $6000-7000 \mathrm{~cm}^{-1}$. Likely, the same happens to the band assigned to the $\mathrm{Cl}(\pi) \rightarrow$ $\operatorname{Ti}\left(d_{\text {eg }}\right)$ transition, which however shifts outside the spectral interval available with our experimental setup. Such shift is in very well agreement with that predicted by Jørgersen by moving from a 6-fold-coordinated $\mathrm{Ti}^{4+}$ to 6 -fold-coordinated $\mathrm{Ti}^{3+}$ sites. ${ }^{98,99}$ The almost complete disappearance of the original band indicates that in both cases, in the adopted experimental conditions, almost all of the $\mathrm{Ti}^{4+}$ sites are reduced to $\mathrm{Ti}^{3+}$ by TEAl. It is worth noting that the spectrum of activated $\mathrm{MgCl}_{2} / \mathrm{EB} / \mathrm{TiCl}_{4}$ (Figure $4 \mathrm{~b}$ ) presents two shoulders at 34600 and $29800 \mathrm{~cm}^{-1}$, which are not visible in the spectrum of activated $\mathrm{MgCl}_{2} / \mathrm{TiCl}_{4}$ (Figure 4a). At lower wavenumbers, a weak band appears around $21500 \mathrm{~cm}^{-1}$ with a long tail downward extending to $13000 \mathrm{~cm}^{-1}$ (insets in Figure $4 \mathrm{a}, \mathrm{b})$, which is straightforwardly assigned to a $\mathrm{Ti}\left(\mathrm{dt}_{2 \mathrm{~g}}\right) \rightarrow$ 
$\mathrm{Ti}\left(\mathrm{d}_{\mathrm{eg}}\right) \mathrm{d}-\mathrm{d}$ transition involving monomeric $\mathrm{Ti}^{3+}$ sites. The energy position of this band is slightly higher than that expected for a $\mathrm{Ti}^{3+}$ site surrounded by chlorine ligands and might indicate the presence of an alkyl group in the $\mathrm{Ti}^{3+}$ coordination sphere, ${ }^{100}$ in accordance with the spectrochemical series of the ligands. ${ }^{101}$

For ZNC (DBP) (Figure 4c), the evolution of the DR UVvis spectrum is similar but not the same. Also, in this case, the intense charge-transfer bands at $29000-26400 \mathrm{~cm}^{-1}$ shift upward of ca. $6000-7000 \mathrm{~cm}^{-1}$ but the phenomenon involves only a fraction of the Ti sites. Moreover, in this case, an intense and broad band appears in the lower energy region, covering the entire $24000-10000 \mathrm{~cm}^{-1}$ range. Similar absorptions have been already observed in $\mathrm{TiCl}_{3}$ salts, ${ }^{48,102,103}$ as described in detail in Section S4. Briefly, those bands are ascribed to intersite transitions of type $2\left(3 \mathrm{~d}^{1}\right) \rightarrow 3 \mathrm{~d}^{0}+3 \mathrm{~d}^{2}$, taking place between vicinal $\mathrm{Ti}^{3+}$ ions connected through a $\mu$-Cl bridge, thus adding a partial charge-transfer character to the $d-d$ transition, which is the reason for the high intensity. ${ }^{104}$ Hence, the observation of those bands denotes the presence of $\mathrm{TiCl}_{3}$ clusters where couples of $\mathrm{Ti}^{3+}$ sites exchange electrons through bridged chlorine ligands. The presence of $\mathrm{TiCl}_{3}$ clusters does not exclude the presence of monomeric $\mathrm{Ti}^{3+}$ sites, which however cannot be identified because their spectroscopic fingerprints are much weaker and overshadowed by those of the $\mathrm{TiCl}_{3}$ clusters. We anticipate that these sites are indeed present, as revealed by NEXAFS, which however does not provide information on the presence of $\mathrm{TiCl}_{3}$ clusters. The lower reducibility of the $\mathrm{Ti}^{4+}$ sites and the simultaneous observation of $\mathrm{TiCl}_{3}$ clusters in the $\mathrm{ZNC}(\mathrm{DBP})$ catalyst, not observed in the other two activated catalysts even though the activation conditions were the same, are two phenomena in apparent contradiction. They can be explained by considering that $\mathrm{ZNC}(\mathrm{DBP})$ is rich in micro- and mesopores. Hence, a fraction of Ti sites may not be accessible by TEAl (at least until the polymer-induced fragmentation typically occurring during the olefin polymerization process takes place), explaining the reduction to a smaller extent. At the same time, the concentration of TEAl inside the accessible pores could cause severe reducing conditions during drying.

Figure 5 shows the $\mathrm{Ti} \mathrm{L}_{2,3}$-edge NEXAFS spectra of $\mathrm{MgCl}_{2} /$ $\mathrm{EB} / \mathrm{TiCl}_{4}$ and $\mathrm{ZNC}(\mathrm{DBP}$ ) before (black) and after (red) addition of TEAl. Starting the discussion from $\mathrm{MgCl}_{2} / \mathrm{EB} /$ $\mathrm{TiCl}_{4}$ (Figure 5a), relevant changes are observed in the $\mathrm{Ti} \mathrm{L}_{2,3}$ edge NEXAFS spectrum after the addition of TEAl, which are better highlighted in Figure $5 \mathrm{a}^{\prime}$, reporting the difference spectrum calculated by subtracting the spectra of the precatalyst from that of the catalyst. In both the $\mathrm{L}_{3}$ and $\mathrm{L}_{2}$ regions, new peaks appear at lower energy with respect to the bands characterizing the spectrum of the precatalyst. Focusing the attention on the $\mathrm{L}_{3}$ edge, we observe the appearance of bands a' at $456.8 \mathrm{eV}$ and $\mathrm{b}^{\prime}$ at $459.2 \mathrm{eV}$ (red arrows in Figure $\left.5 a^{\prime}\right)$ at the expense of bands a and b (black arrows in Figure $\left.5 a^{\prime}\right)$, respectively. On the basis of the literature on titanium oxides, a shift of the $\mathrm{L}_{3}$ edge to lower energy by decreasing the oxidation state of $\mathrm{Ti}$ is expected, of ca. 1.7-2.0 eV per oxidation state. ${ }^{105,106}$ For mixed-valence state titanium oxides, it has been demonstrated that the $\mathrm{L}_{3}$ energy position is in between those of the end-member $\mathrm{Ti}^{3+}$ and $\mathrm{Ti}^{4+}$ compounds. Hence, we interpret these changes as due to the conversion of a fraction of the $\mathrm{Ti}^{4+}$ sites into monomeric $\mathrm{Ti}^{3+}$, in qualitative agreement with the DR UV-vis results. The fact that not all the $\mathrm{Ti}^{4+}$ is reduced to $\mathrm{Ti}^{3+}$, which occurs during the DR UV-
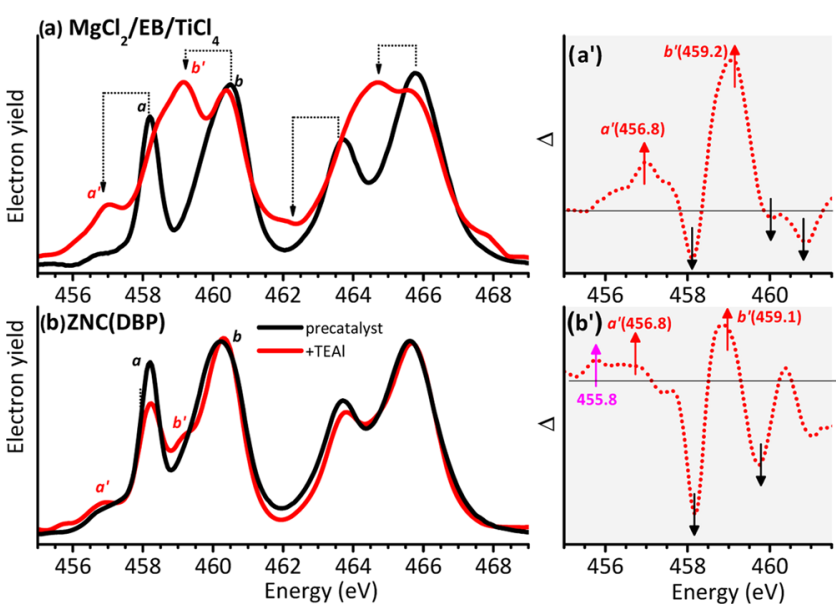

Figure 5. (a) $\mathrm{Ti} \mathrm{L}_{3,2}$-edge NEXAFS spectra of the $\mathrm{MgCl}_{2} / \mathrm{EB} / \mathrm{TiCl}_{4}$ precatalyst (black) and of the same after activation with TEAl, Al/Ti $=2: 1$ (red). $\left(\mathrm{a}^{\prime}\right)$ Difference spectrum calculated by subtracting the spectrum of the precatalyst from that of the catalyst, in the $\mathrm{L}_{3}$ edge region. (b) and $\left(b^{\prime}\right)$ The same as (a) and $\left(a^{\prime}\right)$ for the $\mathrm{ZNC}(\mathrm{DBP})$ sample. Arrows in $\left(a^{\prime}\right)$ and $\left(d^{\prime}\right)$ indicate the bands that increase (red) and decrease (black) in intensity after activation by TEAl.

vis experiment, is ascribed to the different experimental setup. The larger volumes and the complexity of the cell make the NEXAFS setup less easy to be cleaned from moisture traces. Hence, a fraction of TEAl might have acted as a scavenger, instead of as a reductant. Finally, it is interesting to notice that band $b^{\prime}$ is much more intense than band $a^{\prime}$, while the relative intensity of bands a and $b$ in the spectrum of the precatalyst was almost the same. This is due to the fact that the low-lying $\mathrm{dt}_{2 \mathrm{~g}}$ orbital is half-filled for a $\mathrm{Ti}^{3+}$ site. Hence, the probability of a $\operatorname{Ti}(2 p) \rightarrow \operatorname{Ti}\left(\mathrm{dt}_{2 \mathrm{~g}}\right)$ electronic transition is lower than for a $\mathrm{Ti}^{4+}$ site, where the $\mathrm{dt}_{2 \mathrm{~g}}$ orbitals are totally empty. The average $\mathrm{dt}_{2 \mathrm{~g}}-\mathrm{de}_{\mathrm{g}}$ crystal field splitting values for these $\mathrm{Ti}^{3+}$ sites as evaluated by NEXAFS is $2.45 \mathrm{eV}$.

For $\mathrm{ZNC}(\mathrm{DBP})$ (Figure $\left.5 \mathrm{~b}, \mathrm{~b}^{\prime}\right)$, much fewer changes are observed in the $\mathrm{Ti} \mathrm{L}_{2,3}$-edge NEXAFS spectrum after the addition of TEAl. Only a small decrease in the intensity of bands $a$ and $b$ is observed (black arrows in Figure $5 b^{\prime}$ ), accompanied by the appearance of weak bands at 456.8 and $459.1 \mathrm{eV}$ (bands $\mathrm{a}^{\prime}$ and $\mathrm{b}^{\prime}$, red arrows in Figure $5 \mathrm{~b}^{\prime}$ ). Both observations indicate that, in this case, a small fraction of $\mathrm{Ti}^{4+}$ sites is reduced by TEAl to monomeric $\mathrm{Ti}^{3+}$ species. Nevertheless, the apparent insensitivity of the NEXAFS spectrum to the effect of TEAl has an additional explanation. According to the analysis of the DR UV-vis spectra shown in Figure $4 \mathrm{c}$, activation of $\mathrm{ZNC}(\mathrm{DBP})$ by TEAl promotes the formation of $\mathrm{TiCl}_{3}$-like clusters. In this case, the NEXAFS spectrum is not expected to change dramatically, as shown in Figure S7 for $\mathrm{TiCl}_{3}$ polymorphs and discussed in Section S4. This hypothesis is confirmed by the appearance of a weak band at $455.8 \mathrm{eV}$ (pink arrow in Figure $5 b^{\prime}$ ), which is peculiar to the violet $\alpha$-form of $\mathrm{TiCl}_{3}$. Finally, the formation of $\mathrm{TiCl}_{3}$-like clusters likely occurs within the pores of the catalyst, so that they can escape detection by TEY NEXAFS.

To interpret the main features in the experimental UV-vis and NEXAFS spectra of the activated catalysts in Figures 4 and 5 , we have simulated the spectra of five models representative of the possible Ti species formed upon reaction of TEAl with a monomeric 6-fold-coordinated $\mathrm{Ti}^{4+}$ species (Figure $\mathrm{S} 1$ ), so that it is possible to identify which are the models better 

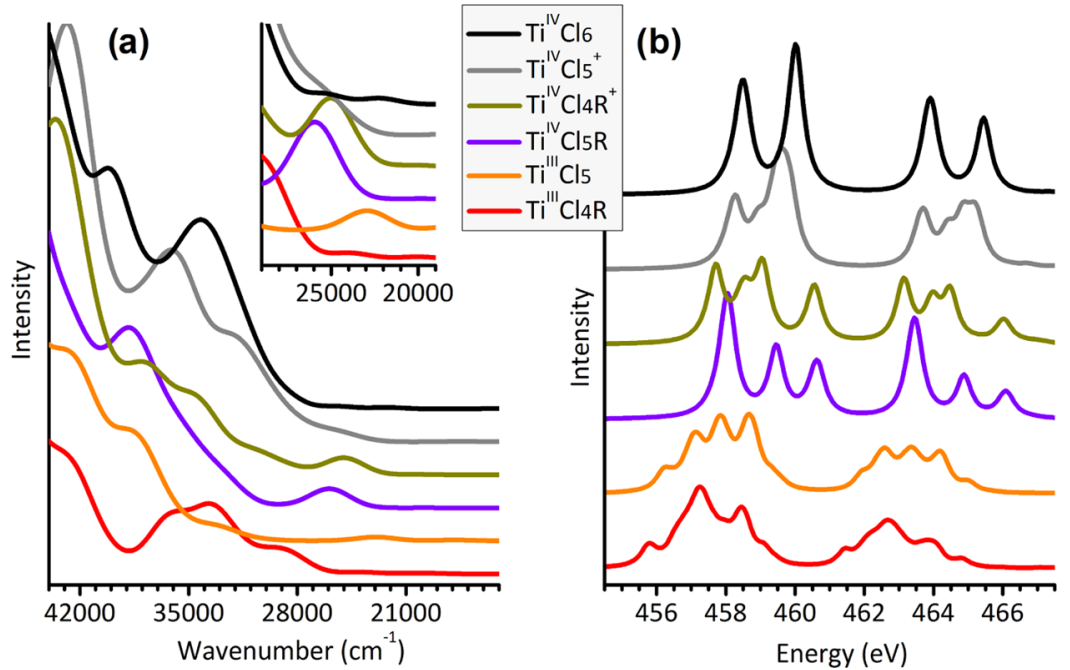

Figure 6. Simulated UV-vis (a) and $\mathrm{Ti}_{2,3}$-edge NEXAFS (b) spectra for five models (Figure S1) representative of the possible Ti species formed upon reaction of TEAl with the hexa-1 model (here labeled as $\mathrm{Ti}^{\mathrm{IV}} \mathrm{Cl}_{6}$ ).
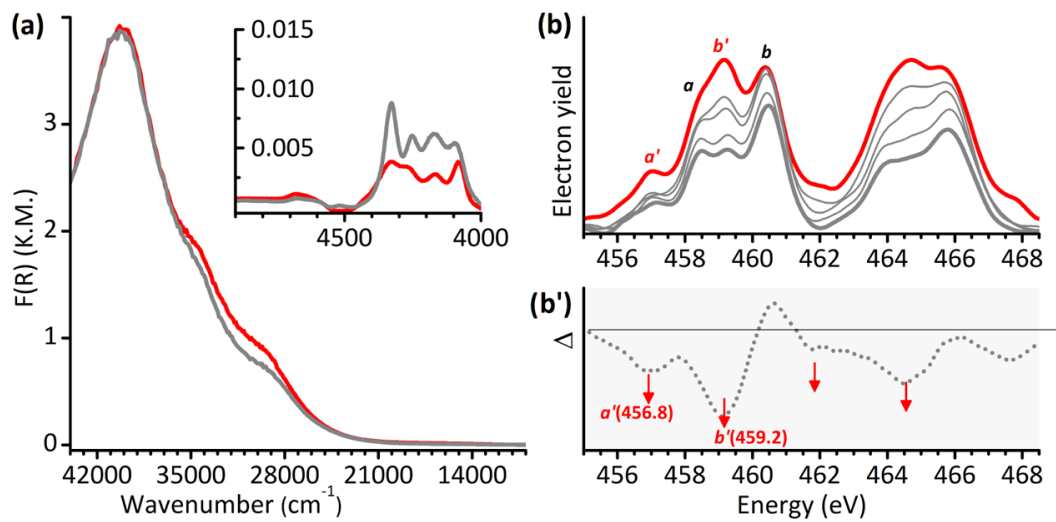

Figure 7. DR UV-vis (a) and $\mathrm{Ti} \mathrm{L}_{3,2}$-edge NEXAFS (b) spectra of the $\mathrm{MgCl}_{2} / \mathrm{EB} / \mathrm{TiCl}_{4}$ catalyst activated by $\mathrm{TEAl}, \mathrm{Al} / \mathrm{Ti}=2: 1$ (red) and evolution of the spectra upon addition of ethylene in the reaction cell (gray). The inset in (a) displays a magnification of the NIR region. ( $b^{\prime}$ ) Difference spectrum calculated by subtracting the spectrum of the catalyst from the first one collected after ethylene polymerization. Arrows in $\left(b^{\prime}\right)$ indicate the bands that decrease in intensity after activation by TEAl.

accounting for the experimentally observed features, as well as to discard less-probable structures. Starting from UV-vis spectra, the spectrum of $\mathrm{Ti}^{\mathrm{IV}} \mathrm{Cl}_{5}{ }^{\oplus}$ shows an intense CT band at lower energy with respect to the starting $\mathrm{Ti}^{\mathrm{IV}} \mathrm{Cl}_{6}$, whereas experimentally the CT bands shift to higher energy upon activation by TEAl. Hence, the presence of $\mathrm{Ti}^{\mathrm{iV}} \mathrm{Cl}_{5}{ }^{\oplus}$-like species is discarded. On the contrary, all of the other simulated $\mathrm{UV}$-vis spectra are compatible with the experimental ones. In particular, the spectrum of $\mathrm{Ti}^{\mathrm{III}} \mathrm{Cl}_{5}$ is the one that better reproduces the experimentally observed band at $21500 \mathrm{~cm}^{-1}$ ( $d-d$ transition), while the spectrum of $\mathrm{Ti}^{\mathrm{III}} \mathrm{Cl}_{4} \mathrm{R}$ is the one that mostly accounts for the two shoulders at 34600 and $29800 \mathrm{~cm}^{-1}$ observed in the spectrum of the $\mathrm{MgCl}_{2} / \mathrm{EB} / \mathrm{TiCl}_{4}$ catalyst.

Figure $6 \mathrm{~b}$ shows the simulated NEXAFS spectra for the same models. The spectrum of $\mathrm{Ti}^{\mathrm{IV}} \mathrm{Cl}_{5}{ }^{\oplus}$ does not divert too much from that of $\mathrm{Ti}^{\mathrm{IV}} \mathrm{Cl}_{6}$, with the two main features of both $\mathrm{L}$ edges slightly shifted to lower energies; this would be compatible with the residual bands a and $b$ in Figure 5, but that model was already discarded by UV-vis spectroscopy. Both $\mathrm{Ti}^{\mathrm{IV}} \mathrm{Cl}_{4} \mathrm{R}^{\oplus}$ and $\mathrm{Ti}^{\mathrm{IV}} \mathrm{Cl}_{5} \mathrm{R}$ models display a third feature per $\mathrm{L}$ edge at higher energy, not compatible with the experimental spectra so that the presence of those $\mathrm{Ti}$ species in the activated catalysts is excluded. Finally, $\mathrm{Ti}^{\mathrm{III}} \mathrm{Cl}_{5}$ and $\mathrm{Ti}^{\mathrm{III}} \mathrm{Cl}_{4} \mathrm{R}$ models have NEXAFS signals quite complex and similar to each other. Both spectra show four bands for each $\mathrm{L}$ edge, shifted to lower energy with respect to the spectrum of the starting $\mathrm{Ti}^{\mathrm{IV}} \mathrm{Cl}_{6}$ model, which account well for the experimentally observed bands $\mathrm{a}^{\prime}$ and $\mathrm{b}^{\prime}$ (in particular, $\mathrm{a}^{\prime}$ is very well reproduced by the $\mathrm{Ti}^{\mathrm{III}} \mathrm{Cl}_{4} \mathrm{R}$ model).

All in all, the experimental DR UV-vis and NEXAFS data coupled with DFT simulation clearly indicate that the majority of the $\mathrm{Ti}$ sites in $\mathrm{MgCl}_{2} / \mathrm{TiCl}_{4}$ and $\mathrm{MgCl}_{2} / \mathrm{EB} / \mathrm{TiCl}_{4}$ are reduced by TEAl mostly to monomeric penta-coordinated $\mathrm{Ti}^{\mathrm{III}} \mathrm{Cl}_{5}$ species, but also, to a minor extent, to alkylated $\mathrm{Ti}^{\mathrm{III}} \mathrm{Cl}_{4} \mathrm{R}$ ones. Other species, such as $\mathrm{Ti}^{\mathrm{IV}} \mathrm{Cl}_{5}{ }^{\oplus}, \mathrm{Ti}^{\mathrm{IV}} \mathrm{Cl}_{4} \mathrm{R}^{\oplus}$, and $\mathrm{Ti}^{\mathrm{IV}} \mathrm{Cl}_{5} \mathrm{R}$ look much less probable. In $\mathrm{ZNC}(\mathrm{DBP})$, instead, TEAl promotes the formation of small $\mathrm{TiCl}_{3}$ clusters (i.e., species where couples of $\mathrm{Ti}^{3+}$ sites share a bridged $\mathrm{Cl}$ ligand), whose contribution dominates the UV-vis spectrum. Nevertheless, NEXAFS reveals that also in this case a minor amount of monomeric $\mathrm{Ti}^{3+}$ species is formed.

3.3. Identification of Active Sites: In Situ Ethylene Polymerization. The experimentally detected $\mathrm{Ti}^{\mathrm{III}} \mathrm{Cl}_{4} \mathrm{R}$ sites satisfy all of the conditions required by the Cossee-Arlman mechanism to be active in ethylene polymerization, ${ }^{42}$ while the 
$\mathrm{Ti}^{\mathrm{iII}} \mathrm{Cl}_{5}$ species, being not alkylated, are not expected to participate in it. To demonstrate the involvement of the former in the ethylene polymerization reaction, we measured the DR UV-vis and NEXAFS spectra after/during the initial stages of ethylene polymerization under very mild conditions, representative of prepolymerization conditions adopted in industrial processes. Upon ethylene insertion into the $\mathrm{Ti}^{\mathrm{III}}-\mathrm{R}$ bond, we do not expect relevant changes in the electronic features of the active sites since a polymeric chain is not dissimilar from the alkyl group R. Nevertheless, in the initial stages of the reaction, the formed PE has the capability to selectively mask the active sites. In DR UV-vis spectroscopy, this happens because the polymer locally changes the scattering properties of the catalyst, ${ }^{107}$ while in TEY-NEXAFS the insulating polymer chains attenuate the photoelectrons escaping from the absorbing $\mathrm{Ti}$ atoms (i.e., the active sites). The net result is that, when comparing the spectra collected before with those collected after/during ethylene polymerization, an erosion of a few bands should be observed in the latter: the bands affected by the reaction will be associated with the sites involved in polymer formation, while those unaffected will be ascribed to the sites not involved in the polymerization.

Figure 7 shows the evolution of the DR UV-vis and $\mathrm{Ti} \mathrm{L}_{2,3^{-}}$ edge NEXAFS spectra upon ethylene polymerization on the $\mathrm{MgCl}_{2} / \mathrm{EB} / \mathrm{TiCl}_{4}$ catalyst activated by TEAl. An analogous sequence has been obtained for the TEAl-activated ZNC(DBP) catalyst, as reported in Figure S8. In the DR UV-vis spectrum (Figure 7a), ethylene polymerization (testified by the appearance in the NIR region of the PE fingerprints grown over the signals of the alkyl groups already present in the catalyst, inset) causes the selective erosion of the bands at 34600 and $29800 \mathrm{~cm}^{-1}$, which can thus be ascribed to the Ti sites involved in the catalysis. It is worth recalling that the simulated spectrum better accounting for those two bands is the spectrum of the $\mathrm{Ti}^{\mathrm{III}} \mathrm{Cl}_{4} \mathrm{R}$ model (Figure 6).

In the NEXAFS experiment (Figure $7 \mathrm{~b}$ ), ethylene polymerization was carried out by sending ethylene pulses on the catalyst and collecting a spectrum after each pulse. It is worth noting that the total intensity of the NEXAFS spectra decreases along with the sequence, but bands $a^{\prime}$ and $b^{\prime}$ decrease faster than bands $a$ and $b$. This is well evident by looking at the difference spectrum in Figure $7 b^{\prime}$, which was calculated by subtracting the spectrum of the catalyst from that measured after the first ethylene pulse. The overall decrease in intensity is associated with the formation of a layer of polyethylene on all of the catalyst particles. However, the bands ascribed to monomeric $\mathrm{Ti}^{3+}$ sites are those decreasing faster (and basically the only ones affected after the first ethylene pulse). The sequence of NEXAFS spectra indicates that a consistent fraction of the monomeric $\mathrm{Ti}^{3+}$ sites is active in ethylene polymerization. Similar behavior is observed for the ZNC(DBP) catalyst (Figure S8b), where however the decrease of bands $a^{\prime}$ and $b^{\prime}$ is less evident, the NEXAFS spectrum being dominated by the unreactive $\mathrm{TiCl}_{3}$-like clusters.

\section{CONCLUSIONS}

In this contribution, we reported a thorough characterization of the electronic properties of the $\mathrm{Ti}$ sites in three $\mathrm{ZN}$ precatalysts with an increasing degree of complexity, and in the corresponding catalysts obtained upon activation with TEAl. In particular, we have analyzed two model samples $\left(\mathrm{MgCl}_{2} / \mathrm{TiCl}_{4}\right.$ and $\mathrm{MgCl}_{2} / \mathrm{EB} / \mathrm{TiCl}_{4}$ ) and an industrial-like one (ZNC(DBP)). DR UV-vis and Ti $\mathrm{L}_{2,3}$-edge NEXAFS spectroscopy, combined with theoretical calculations, provided compelling evidence for the presence of monomeric 6-fold-coordinated $\mathrm{Ti}^{4+}$ species in all of the three precatalysts, categorized in at least two main families characterized by slightly different structural parameters. In particular, the experimental data are not only compatible with hexa-coordinated $\mathrm{Ti}^{4+}$ species on $\mathrm{MgCl}_{2}(110)$ or equivalent surfaces, but also with the structure proposed in the theoretical work by Cavallo and co-workers, ${ }^{41}$ which originates from chemisorption of $\mathrm{TiCl}_{4}$ at a step defect on the thermodynamically more stable (104) surface. Tichloride dimers and 5-fold-coordinated $\mathrm{Ti}^{4+}$ species have been discarded since their spectroscopic fingerprints are not compatible with the experimental data. While a number of excellent theoretical works at present support 6-fold-coordinated $\mathrm{Ti}^{4+}$ sites on the $\mathrm{MgCl}_{2}(110)$ surface or analogous ones as the most probable types of sites in $\mathrm{MgCl}_{2}$-based $\mathrm{ZN}$ catalysts, the theoretical models still lack a direct experimental validation. The observation of well-defined monomeric sites in heterogeneous $\mathrm{ZN}$ precatalysts and in particular in the industrial one is remarkable by itself, considering the complexity of the catalyst formulation. Moreover, DR UVvis and $\mathrm{Ti} \mathrm{L}_{2,3}$ NEXAFS spectra allowed us to estimate the crystal-field splitting between the $\mathrm{d}$ orbitals of $\mathrm{Ti}$, and from there the effective positive charge on the $\mathrm{Ti}$ sites, which is different in the three precatalysts and higher in the industrial one. Determining experimentally the effective charge state of the $\mathrm{Ti}^{4+}$ sites in $\mathrm{ZN}$ precatalysts is relevant for catalysis because it correlates with the activation energy for olefin insertion into the Ti-alkyl bond formed after activation.

After activation by TEAl, the majority of the $\mathrm{Ti}^{4+}$ sites in the two model catalysts are reduced to monomeric 5-coordinated $\mathrm{Ti}^{3+}$ sites, either in the form $\mathrm{Ti}^{\mathrm{III}} \mathrm{Cl}_{5}$ (i.e., with a coordination vacancy but not alkylated) or in the form $\mathrm{Ti}^{\mathrm{III}} \mathrm{Cl}_{4} \mathrm{R}$ (i.e., with both a coordination vacancy and an alkyl group). The latter, less abundant, are the sites involved in ethylene polymerization, as demonstrated by experiments performed in the presence of ethylene. In the industrial catalyst, instead, TEAl reduces only a fraction of the $\mathrm{Ti}^{4+}$ sites, forming both monomeric 5-coordinated $\mathrm{Ti}^{\mathrm{III}} \mathrm{Cl}_{4} \mathrm{R}$ species active in ethylene polymerization and small inactive $\mathrm{TiCl}_{3}$-like clusters. The lower reducibility of the $\mathrm{Ti}^{4+}$ sites and the co-presence of $\mathrm{TiCl}_{3}$ clusters is explained by considering the porous nature of the industrial catalyst. It is worth noticing that, although $\mathrm{Ti}^{\mathrm{III}}$-alkyl species have been proposed a long time ago as key intermediates in olefin polymerization, their unambiguous characterization has represented one of the main challenges in the last 60 years. Recently, pulse EPR spectroscopy combined with DFT calculations was adopted to characterize in detail the molecular and supported $\mathrm{Ti}^{\mathrm{III}}$-alkyl complexes, ${ }^{108,109}$ as well as industrial $\mathrm{ZN}$ catalysts, ${ }^{110,111}$ providing structural details that are in good agreement with our findings. However, with respect to EPR that selectively detects only a fraction of the $\mathrm{Ti}$ sites (those paramagnetically active), UV-vis and $\mathrm{L}_{2,3}$-edge NEXAFS spectroscopy provide information on all of the Ti sites, including those inactive in catalysis but which, nevertheless, are part of the catalyst body. We remark here that a careful analysis of the data collected before and during/after ethylene polymerization allows the isolation of the spectroscopic fingerprints of the active sites from those of the inactive ones.

As a general remark, the present work has prompted the development of new experimental setups and theoretical methodologies to fully exploit the potentials of two electronic 
spectroscopies, UV-vis and NEXAFS, in providing direct information on the nature of the Ti sites in ZN precatalysts, on their changes in the presence of the aluminum-alkyl activator and during ethylene polymerization. Both methods allow the detection of all of the $\mathrm{Ti}$ sites present in the samples at each catalytic stage, at the same time discriminating between active and inactive species. The application of these techniques to a platform of $\mathrm{ZN}$ catalysts of industrial interest under different conditions will represent a new powerful tool for disclosing the black box of the $\mathrm{ZN}$ catalytic process, even under reaction conditions.

\section{ASSOCIATED CONTENT}

\section{(s) Supporting Information}

The Supporting Information is available free of charge at https://pubs.acs.org/doi/10.1021/acscatal.1c01735.

Structural models; additional data on the electronic properties of the precatalysts; correlation between NEXAFS and UV-vis spectroscopy; electronic properties of $\mathrm{TiCl}_{3}$ polymorphs; and ethylene polymerization on the TEAl-activated $\mathrm{ZNC}(\mathrm{DBP})$ catalyst (PDF)

\section{AUTHOR INFORMATION}

\section{Corresponding Author}

Elena Groppo - Department of Chemistry, INSTM and NIS Centre, University of Torino, 10125 Torino, Italy; DPI, 5600 AX Eindhoven, The Netherlands; (1) orcid.org/0000-00034153-5709; Email: elena.groppo@unito.it

\section{Authors}

Alessandro Piovano - Department of Chemistry, INSTM and NIS Centre, University of Torino, 10125 Torino, Italy; DPI, 5600 AX Eindhoven, The Netherlands; (c) orcid.org/00000002-5784-6897

Matteo Signorile - Department of Chemistry, INSTM and NIS Centre, University of Torino, 10125 Torino, Italy; (1) orcid.org/0000-0003-0521-3702

Luca Braglia - CNR-IOM, TASC Laboratory, 34149 Trieste, Italy

Piero Torelli - CNR-IOM, TASC Laboratory, 34149 Trieste, Italy

Andrea Martini - Department of Chemistry, INSTM and NIS Centre, University of Torino, 10125 Torino, Italy; The Smart Materials Research Institute, Southern Federal University, 344090 Rostov-on-Don, Russia; @ orcid.org/0000-00018820-2157

Toru Wada - DPI, 5600 AX Eindhoven, The Netherlands; Graduate School of Advanced Science and Technology, Japan Advanced Institute of Science and Technology, Nomi, Ishikawa 923-1292, Japan; ○ orcid.org/0000-0001-92191307

Gentoku Takasao - Graduate School of Advanced Science and Technology, Japan Advanced Institute of Science and Technology, Nomi, Ishikawa 923-1292, Japan

Toshiaki Taniike - DPI, 5600 AX Eindhoven, The Netherlands; Graduate School of Advanced Science and Technology, Japan Advanced Institute of Science and Technology, Nomi, Ishikawa 923-1292, Japan; 이이.org/ 0000-0002-4870-837X

Complete contact information is available at: https://pubs.acs.org/10.1021/acscatal.1c01735

\section{Notes}

The authors declare no competing financial interest.

\section{ACKNOWLEDGMENTS}

The work of A.P., T.W., T.T., and E.G. forms part of the research program of DPI, project \#802. The work of A.M., L.B., and P.T. forms part of project no. 2017KKP5ZR PRIN2017 MOSCATo. The work of G.T. was supported by JSPS KAKENHI Grant Number JP20J15042. The authors acknowledge the $\mathrm{C} 3 \mathrm{~S}$ consortium for granting computational resources on the OCCAM cluster, funded by the Compagnia di San Paolo. This work has been partly performed in the framework of the Nanoscience Foundry and Fine Analysis (NFFA-MIUR Italy Progetti Internazionali) facility. The NEXAFS experiments could not have been performed without the inspiration and strong support of our beloved Carlo Lamberti, who strongly believed in the potential of the method since the beginning, despite many discouraging results during the initial beamtimes. This work is the consecration of his efforts.

\section{REFERENCES}

(1) Baker, I. Polypropylene. In Fifty Materials That Make the World; Springer: Cham, 2018.

(2) Albizzati, E.; Giannini, U.; Collina, G.; Noristi, L.; Resconi, L. Catalysts and Polymerizations. In Polypropylene Handbook; Moore, E. P. J., Ed.; Hanser-Gardner Publications: Cincinnati (Ohio, USA), 1996.

(3) Busico, V. Giulio Natta and the Development of Stereoselective Propene Polymerization. In Polyolefins: 50 years after Ziegler and Natta I; Kaminsky, W., Ed.; Springer: Berlin, 2013; Vol. 257, pp 37-57.

(4) Stürzel, M.; Mihan, S.; Mülhaupt, R. From Multisite Polymerization Catalysis to Sustainable Materials and All-Polyolefin Composites. Chem. Rev. 2016, 116, 1398-1433.

(5) Kumawat, J.; Gupta, V. K. Fundamental aspects of heterogeneous Ziegler-Natta olefin polymerization catalysis: an experimental and computational overview. Polym. Chem. 2020, 11, 6107-6128.

(6) Galli, P.; Vecellio, G. Technology: driving force behind innovation and growth of polyolefins. Prog. Polym. Sci. 2001, 26, $1287-1336$

(7) Busico, V.; Cipullo, R.; Mingione, A.; Rongo, L. Accelerating the Research Approach to Ziegler-Natta Catalysts. Ind. Eng. Chem. Res. 2016, 55, 2686-2695.

(8) Noristi, L.; Marchetti, E.; Baruzzi, G.; Sgarzi, P. Investigation on the particle growth mechanism in propylene polymerization with $\mathrm{MgCl}$-supported Ziegler-Natta catalysts. J. Polym. Sci., Part A: Polym. Chem. 1994, 32, 3047-3059.

(9) Busico, V.; Causà, M.; Cipullo, R.; Credendino, R.; Cutillo, F.; Friederichs, N.; Lamanna, R.; Segre, A.; Van Axel Castelli, V. Periodic DFT and high-resolution magic-angle-spinning (HR-MAS) H-1 NMR investigation of the active surfaces of $\mathrm{MgCl} 2$-supported Ziegler-Natta catalysts. The $\mathrm{MgCl} 2$ matrix. J. Phys. Chem. C 2008, 112, 1081-1089.

(10) Taniike, T.; Thang, V. Q.; Binh, N. T.; Hiraoka, Y.; Uozumi, T.; Terano, M. Initial Particle Morphology Development in ZieglerNatta Propylene Polymerization Tracked with Stopped-Flow Technique. Macromol. Chem. Phys. 2011, 212, 723-729.

(11) Taniike, T.; Funako, T.; Terano, M. Multilateral characterization for industrial Ziegler-Natta catalysts toward elucidation of structure-performance relationship. J. Catal. 2014, 311, 33-40.

(12) Blaakmeer, E. S.; Antinucci, G.; Busico, V.; Van Eck, E. R. H.; Kentgens, A. P. M. Solid-State NMR Investigations of $\mathrm{MgCl} 2$ Catalyst Support. J. Phys. Chem. C 2016, 120, 6063-6074.

(13) Chammingkwan, P.; Terano, M.; Taniike, T. High-Throughput Synthesis of Support Materials for Olefin Polymerization Catalyst. ACS Comb. Sci. 2017, 19, 331-342.

(14) Breuza, E.; Antinucci, G.; Budzelaar, P. H. M.; Busico, V.; Correa, A.; Ehm, C. MgCl2-Supported Ziegler-Natta Catalysts: a 
DFT-D "Flexible-Cluster" Approach to Internal Donor Adducts. J. Phys. Chem. C 2018, 122, 9046-9053.

(15) Taniike, T.; Terano, M. The Use of Donors to Increase the Isotacticity of Polypropylene. Adv. Polym. Sci. 2013, 257, 81-98.

(16) Bart, J. C. J. Activation of Magnesium Chloride by Dry Milling. J. Mater. Sci. 1993, 28, 278-284.

(17) Delogu, F.; Mulas, G.; Schiffini, L.; Cocco, G. Mechanical work and conversion degree in mechanically induced processes. Mater. Sci. Eng., A 2004, 382, 280-287.

(18) Galli, P.; Barbé, P. C.; Guidetti, G.; Zannetti, R.; Marigo, A.; Bergozza, M.; Fichera, A. The activation of MgCl2-supported ZieglerNatta catalysts: A structural investigation. Eur. Polym. Chem. 1983, 19, 19-24.

(19) Noristi, L.; Barbè, P. C.; Baruzzi, G. Effect of the internal/ external donor pair in high-yield catalysts for propylene polymerization, 1. Catalyst-cocatalyst interactions. Makromol. Chem. 1991, 192, 1115-1127.

(20) Soga, K.; Ohgizawa, M.; Shiono, T. Copolymerization of ethylene and propene with a $\mathrm{TiCl} 4 / \mathrm{MgCl} 2-\mathrm{Al}(\mathrm{C} 2 \mathrm{H} 5) 3$ catalyst system using a stopped-flow method. Makromol. Chem. 1993, 194, $2173-2181$.

(21) Brambilla, L.; Zerbi, G.; Nascetti, S.; Piemontesi, F.; Morini, G. Experimental and Calculated Vibrational Spectra and Structure of Ziegler-Natta Catalyst Precursor: 50/1 Comilled $\mathrm{MgCl} 2-\mathrm{TiCl} 4$. Macromol. Symp. 2004, 213, 287-301.

(22) Brambilla, L.; Zerbi, G.; Piemontesi, F.; Nascetti, S.; Morini, G. Structure of MgCl2-TiCl4 complex in co-milled Ziegler-Natta catalyst precursors with different $\mathrm{TiCl} 4$ content: Experimental and theoretical vibrational spectra. J. Mol. Catal. A: Chem. 2007, 263, 103-111.

(23) Chung, J. S.; Song, I. K.; Lee, W. Y.; Park, H. M. Morphology control of a $\mathrm{MgCl}_{2}$-supported Ziegler-Natta catalyst by the recrystallization method. Macromol. Chem. Phys. 1995, 196, 12051210.

(24) Choi, J. H.; Chung, J. S.; Shin, H. W.; Song, I. K.; Lee, W. Y. The effect of alcohol treatment in the preparation of $\mathrm{MgCl} 2$ support by a recrystallization method on the catalytic activity and isotactic index for propylene polymerization. Eur. Polym. J. 1996, 32, 405-410.

(25) Parada, A.; Rajmankina, T.; Chirinos, J. Study of the $\mathrm{MgCl} 2$ recrystallization conditions on Ziegler-Natta catalyst properties. Polym. Bull. 1999, 43, 231-238.

(26) Pokasermsong, P.; Piyasan, P. Comparison of Activity of Ziegler-Natta Catalysts Prepared by Recrystallization and Chemical Reaction Methods towards Polymerization of Ethylene. Eng. J. 2009, 13, 57-64.

(27) Lee, D. H.; Jeong, Y. T.; Soga, K. In situ formation of magnesium chloride support and internal donor during preparation of propylene polymerization catalysts. Ind. Eng. Chem. Res. 1992, 31, 2642-2647.

(28) Dashti, A.; Ramazani, Sa. A.; Hiraoka, Y.; Kim, S. Y.; Taniike, T.; Terano, M. Kinetic and morphological study of a magnesium ethoxide-based Zieglerâ€ "Natta catalyst for propylene polymerization. Polym. Int. 2009, 58, 40-45.

(29) Funako, T.; Chammingkwan, P.; Taniike, T.; Terano, M. Alternation of Pore Architecture of Ziegler-Natta Catalysts through Modification of Magnesium Ethoxide. Macromol. React. Eng. 2015, 9, $325-332$.

(30) Klaue, A.; Kruck, M.; Friederichs, N.; Bertola, F.; Wu, H.; Morbidelli, M. Insight into the Synthesis Process of an Industrial Ziegler-Natta Catalyst. Ind. Eng. Chem. Res. 2019, 58, 886-896.

(31) Wada, T.; Takasao, G.; Piovano, A.; D’Amore, M.; Thakur, A.; Chammingkwan, P.; Bruzzese, P. C.; Terano, M.; Civalleri, B.; Bordiga, S.; Groppo, E.; Taniike, T. Revisiting the identity of $\delta$ $\mathrm{MgCl2}$ : Part I. Structural disorder studied by synchrotron X-ray total scattering. J. Catal. 2020, 386, 76-86.

(32) Piovano, A.; D’Amore, M.; Wada, T.; Bruzzese, P. C.; Takasao, G.; Thakur, A.; Chammingkwan, P.; Terano, M.; Civalleri, B.; Bordiga, S.; Taniike, T.; Groppo, E. Revisiting the identity of $\delta$ $\mathrm{MgCl}$ : Part II. Morphology and exposed surfaces studied by vibrational spectroscopies and DFT calculation. J. Catal. 2020, 387, $1-11$.

(33) Busico, V.; Corradini, P.; De Martino, L.; Proto, A.; Savino, V.; Albizzati, E. Polymerization of propene in the presence of $\mathrm{MgCl}$ supported Ziegler-Natta catalysts, 1 . The role of ethyl benzoate as "internal" and "external" base. Makromol. Chem. 1985, 186, 12791288.

(34) Iiskola, E.; Pelkonen, A.; Kakkonen, H. J.; Pursiainen, J.; Pakkanen, T. A. A novel MgCl2-supported Ziegler-Natta catalyst composition: Stereospecific polymerization of propene without external donor. Makromol. Chem., Rapid Commun. 1993, 14, 133137.

(35) Liu, B.; Nitta, T.; Nakatani, H.; Terano, M. Specific Roles of AlAlkyl Cocatalyst in the Origin of Isospecificity of Active Sites on Donor-Free TiCl4/MgCl2 Ziegler-Natta Catalyst. Macromol. Chem. Phys. 2002, 203, 2412-2421.

(36) Corradini, P.; Guerra, G.; Cavallo, L. Do New Century Catalysts Unravel the Mechanism of Stereocontrol of Old ZieglerNatta catalysts? Acc. Chem. Res. 2004, 37, 231-241.

(37) Busico, V.; Cipullo, R.; Pellecchia, R.; Ronca, S.; Roviello, G.; Talarico, G. Design of stereoselective Ziegler-Natta propene polymerization catalysts. Proc. Natl. Acad. Sci. U.S.A. 2006, 103, 1532115326.

(38) Correa, A.; Piemontesi, F.; Morini, G.; Cavallo, L. Key Elements in the Structure and Function Relationship of the $\mathrm{MgCl}$ / TiCl4/Lewis base Ziegler-Natta Catalytic System. Macromolecules 2007, 40, 9181-9189.

(39) Hiraoka, Y.; Kim, S. Y.; Dashti, A.; Taniike, T.; Terano, M. Similarities and Differences of the Active Sites in Basic and Advanced $\mathrm{MgCl} 2$-Supported Ziegler-Natta Propylene Polymerization Catalysts. Macromol. React. Eng. 2010, 4, 510-515.

(40) Correa, A.; Credendino, R.; Pater, J. T. M.; Morini, G.; Cavallo, L. Theoretical Investigation of Active Sites at the Corners of $\mathrm{MgCl} 2$ Crystallites in Supported Zieglerâ€"Natta Catalysts. Macromolecules 2012, 45, 3695-3701.

(41) Credendino, R.; Liguori, D.; Fan, Z.; Morini, G.; Cavallo, L. Toward a Unified Model Explaining Heterogeneous Ziegler-Natta Catalysis. ACS Catal. 2015, 5, 5431-5435.

(42) Cossee, P. Ziegler-Natta catalysis I. Mechanism of polymerization of $\alpha$-olefins with Ziegler-Natta catalysts. J. Catal. 1964, 3, 8088.

(43) Takasao, G.; Wada, T.; Thakur, A.; Chammingkwan, P.; Terano, M.; Taniike, T. Insight into structural distribution of heterogeneous Ziegler-Natta catalyst from non-empirical structure determination. J. Catal. 2021, 394, 299-306.

(44) Bahri-Laleh, N.; Hanifpour, A.; Mirmohammadi, S. A.; Poater, A.; Nekoomanesh-Haghighi, M.; Talarico, G.; Cavallo, L. Computational modeling of heterogeneous Ziegler-Natta catalysts for olefins polymerization. Prog. Polym. Sci. 2018, 84, 89-114.

(45) Groppo, E.; Seenivasan, K.; Barzan, C. The potential of spectroscopic methods applied to heterogeneous catalysts for olefin polymerization. Catal. Sci. Technol. 2013, 3, 858-878.

(46) Kissin, Y. V.; Liu, X.; Pollick, D. J.; Brungard, N. L.; Chang, M. Ziegler-Natta catalysts for propylene polymerization: Chemistry of reactions leading to the formation of active centers. J. Mol. Catal. A: Chem. 2008, 287, 45-52.

(47) Seenivasan, K.; Sommazzi, A.; Bonino, F.; Bordiga, S.; Groppo, E. Spectroscopic Investigation of Heterogeneous Ziegler-Natta Catalysts: $\mathrm{Ti}$ and $\mathrm{Mg}$ Chloride Tetrahydrofuranates, Their Interaction Compound, and the Role of the Activator. Chem. - Eur. J 2011, 17, $8648-8656$.

(48) Groppo, E.; Gallo, E.; Seenivasan, K.; Sommazzi, A.; Bordiga, S.; Glatzel, P.; Van Silfhout, R.; Kachatkou, A.; Bras, W.; Lamberti, C. XAS and XES techniques shed light on the dark side of Ziegler-Natta catalysts: active sites generation. ChemCatChem 2015, 7, 1432-1437.

(49) Groppo, E.; Seenivasan, K.; Gallo, E.; Sommazzi, A.; Lamberti, C.; Bordiga, S. Activation and In Situ Ethylene Polymerization on Silica-Supported Ziegler-Natta Catalysts. ACS Catal. 2015, 5, 55865595. 
(50) Piovano, A.; Thushara, K. S.; Morra, E.; Chiesa, M.; Groppo, E. Unraveling the Catalytic Synergy between $\mathrm{Ti} 3+$ and $\mathrm{Al} 3+$ Sites on a Chlorinated Al2O3: A Tandem Approach to Branched Polyethylene. Angew. Chem., Int. Ed. 2016, 55, 11203-11206.

(51) Piovano, A.; Morra, E.; Chiesa, M.; Groppo, E. Tuning the $\mathrm{Ti} 3+$ and $\mathrm{Al} 3+$ Synergy in an Al2O3/TiClx Catalyst to Modulate the Grade of the Produced Polyethylene. ACS Catal. 2017, 7, 4915-4921.

(52) Piovano, A.; Pletcher, P.; Velthoen, M. E. Z.; Zanoni, S.; Chung, S.-H.; Bossers, K.; Jongkind, M. K.; Fiore, G.; Groppo, E.; Weckhuysen, B. M. Genesis of $\mathrm{MgCl}$-based Ziegler-Natta Catalysts as Probed with Operando Spectroscopy. ChemPhysChem 2018, 19, 2662-2671.

(53) Amakawa, K.; Sun, L.; Guo, C.; Hävecker, M.; Kube, P.; Wachs, I. E.; Lwin, S.; Frenkel, A. I.; Patlolla, A.; Hermann, K.; Schlögl, R.; Trunschke, A. How Strain Affects the Reactivity of Surface Metal Oxide Catalysts. Angew. Chem., Int. Ed. 2013, 52, 13553-13557.

(54) Cavalleri, M.; Hermann, K.; Knop-Gericke, A.; Hävecker, M.; Herbert, R.; Hess, C.; Oestereich, A.; Döbler, J.; Schlögl, R. Analysis of silica-supported vanadia by X-ray absorption spectroscopy: Combined theoretical and experimental studies. J. Catal. 2009, 262, 215-223.

(55) Gross, E.; Somorjai, G. A. Molecular catalysis science: Nanoparticle synthesis and instrument development for studies under reaction conditions. J. Catal. 2015, 328, 91-101.

(56) Escudero, C.; Salmeron, M. From solid-vacuum to solid-gas and solid-liquid interfaces: In situ studies of structure and dynamics under relevant conditions. Surf. Sci. 2013, 607, 2-9.

(57) Ryo, T.; Hiroshi, K. In-situ observations of catalytic surface reactions with soft $\mathrm{x}$-rays under working conditions. J. Phys.: Condens. Matter 2015, 27, No. 083003.

(58) Latham, K. G.; Dose, W. M.; Allen, J. A.; Donne, S. W. Nitrogen doped heat treated and activated hydrothermal carbon: NEXAFS examination of the carbon surface at different temperatures. Carbon 2018, 128, 179-190.

(59) Giorgianni, G.; Mebrahtu, C.; Schuster, M. E.; Large, A. I.; Held, G.; Ferrer, P.; Venturini, F.; Grinter, D.; Palkovits, R.; Perathoner, S.; Centi, G.; Abate, S.; Arrigo, R. Elucidating the mechanism of the $\mathrm{CO} 2$ methanation reaction over Niâ $€$ "Fe hydrotalcite-derived catalysts via surface-sensitive in situ XPS and NEXAFS. Phys. Chem. Chem. Phys. 2020, 22, 18788-18797.

(60) Signorile, M.; Braglia, L.; Crocellà, V.; Torelli, P.; Groppo, E.; Ricchiardi, G.; Bordiga, S.; Bonino, F. Titanium Defective Sites in TS1: Structural Insights by Combining Spectroscopy and Simulation. Angew. Chem., Int. Ed. 2020, 59, 18145-18150.

(61) Fracchia, M.; Ghigna, P.; Pozzi, T.; Anselmi Tamburini, U.; Colombo, V.; Braglia, L.; Torelli, P. Stabilization by Configurational Entropy of the $\mathrm{Cu}(\mathrm{II})$ Active Site during $\mathrm{CO}$ Oxidation on Mg0.2Co0.2Ni0.2Cu0.2Zn0.2O. J. Phys. Chem. Lett. 2020, 11, $3589-3593$.

(62) Braglia, L.; Fracchia, M.; Ghigna, P.; Minguzzi, A.; Meroni, D.; Edla, R.; Vandichel, M.; Ahlberg, E.; Cerrato, G.; Torelli, P. Understanding Solid-Gas Reaction Mechanisms by Operando Soft X-Ray Absorption Spectroscopy at Ambient Pressure. J. Phys. Chem. C 2020, 124, 14202-14212.

(63) Terano, M.; Soga, H.; Kimura, K. Catalyst for Polymerization of Olefins. U.S. Patent US4,829,0371989.

(64) Castán-Guerrero, C.; Krizmancic, D.; Bonanni, V.; Edla, R.; Deluisa, A.; Salvador, F.; Rossi, G.; Panaccione, G.; Torelli, P. A reaction cell for ambient pressure soft x-ray absorption spectroscopy. Rev. Sci. Instrum. 2018, 89, No. 054101.

(65) Simonne, D. H.; Martini, A.; Signorile, M.; Piovano, A.; Braglia, L.; Torelli, P.; Borfecchia, E.; Ricchiardi, G. THORONDOR: a software for fast treatment and analysis of low-energy XAS data. J. Synchrotron Radiat. 2020, 27, 1741-1752.

(66) Thomas, A.; Fischer, A.; Goettmann, F.; Antonietti, M.; Müller, J.-O.; Schlögl, R.; Carlsson, J. M. Graphitic carbon nitride materials: variation of structure and morphology and their use as metal-free catalysts. J. Mater. Chem. 2008, 18, 4893-4908.
(67) Neese, F. Software update: the ORCA program system, version 4.0. Wiley Interdiscip. Rev.: Comput. Mol. Sci. 2018, 8, No. e1327.

(68) Takasao, G.; Wada, T.; Thakur, A.; Chammingkwan, P.; Terano, M.; Taniike, T. Machine Learning-Aided Structure Determination for $\mathrm{TiCl} 4-\mathrm{Capped} \mathrm{MgCl} 2$ Nanoplate of Heterogeneous Ziegler-Natta Catalyst. ACS Catal. 2019, 9, 2599-2609.

(69) Becke, A. D. A new mixing of Hartree-Fock and local densityfunctional theories. J. Chem. Phys. 1993, 98, 1372-1377.

(70) Lee, C.; Yang, W.; Parr, R. G. Development of the ColleSalvetti correlation-energy formula into a functional of the electron density. Phys. Rev. B 1988, 37, 785-789.

(71) Weigend, F.; Ahlrichs, R. Balanced basis sets of split valence, triple zeta valence and quadruple zeta valence quality for $\mathrm{H}$ to $\mathrm{Rn}$ : Design and assessment of accuracy. Phys. Chem. Chem. Phys. 2005, 7, 3297-3305.

(72) Corradini, P.; Barone, V.; Fusco, R.; Guerra, G. A Possible model of catalytic sites for the stereospecific polymerization of alphaolefins on 1st-generation and supported ziegler-natta catalysts. Gazz. Chim. Ital. 1983, 113, 601-607.

(73) Monaco, G.; Toto, M.; Guerra, G.; Corradini, P.; Cavallo, L. Geometry and stability of titanium chloride species adsorbed on the (100) and (110) cuts of the $\mathrm{MgCl} 2$ support of the heterogeneous Ziegler-Natta catalysts. Macromolecules 2000, 33, 8953-8962.

(74) D’Amore, M.; Credendino, R.; Budzelaar, P. H. M.; Causá, M.; Busico, V. A periodic hybrid DFT approach (including dispersion) to $\mathrm{MgCl}$-supported Ziegler-Natta catalysts - 1: TiCl4 adsorption on $\mathrm{MgCl} 2$ crystal surfaces. J. Catal. 2012, 286, 103-110.

(75) D’Amore, M.; Thushara, K. S.; Piovano, A.; Causà, M.; Bordiga, S.; Groppo, E. Surface Investigation and Morphological Analysis of Structurally Disordered $\mathrm{MgCl} 2$ and $\mathrm{MgCl} 2 / \mathrm{TiCl} 4$ Ziegler-Natta Catalysts. ACS Catal. 2016, 6, 5786-5796.

(76) Taniike, T.; Terano, M. Coadsorption model for first-principle description of roles of donors in heterogeneous Ziegler-Natta propylene polymerization. J. Catal. 2012, 293, 39-50.

(77) Shetty, S. Synergistic, reconstruction and bonding effects during the adsorption of internal electron donors and TiCl4 on $\mathrm{MgCl} 2$ surface: A periodic-DFT investigation. Surf. Sci. 2016, 653, $55-65$.

(78) Iijima, T.; Shimizu, T.; Goto, A.; Deguchi, K.; Nakai, T.; Ohashi, R.; Saito, M. 47,49Ti solid-state NMR and DFT study of Ziegler-Natta catalyst: Adsorption of TiCl4 molecule onto the surface of $\mathrm{MgCl}$. J. Phys. Chem. Solids 2019, 135, No. 109088.

(79) Grimme, S. A simplified Tamm-Dancoff density functional approach for the electronic excitation spectra of very large molecules. J. Chem. Phys. 2013, 138, No. 244104.

(80) Roemelt, M.; Neese, F. Excited States of Large Open-Shell Molecules: An Efficient, General, and Spin-Adapted Approach Based on a Restricted Open-Shell Ground State Wave function. J. Phys. Chem. A 2013, 117, 3069-3083.

(81) van Wüllen, C. Molecular density functional calculations in the regular relativistic approximation: Method, application to coinage metal diatomics, hydrides, fluorides and chlorides, and comparison with first-order relativistic calculations. J. Chem. Phys. 1998, 109, 392-399.

(82) Casarin, M.; Finetti, P.; Vittadini, A.; Wang, F.; Ziegler, T. Spin-Orbit Relativistic Time-Dependent Density Functional Calculations of the Metal and Ligand Pre-Edge XAS Intensities of Organotitanium Complexes: $\mathrm{TiCl} 4, \mathrm{Ti}(\eta 5-\mathrm{C} 5 \mathrm{H} 5) \mathrm{Cl} 3$, and $\mathrm{Ti}(\eta 5-$ C5H5)2Cl2. J. Phys. Chem. A 2007, 111, 5270-5279.

(83) Note that the Ti loading is different in the three pre-catalysts.

(84) Figgis, B. N., Introduction to Ligand Fields; John Wiley \& Sons: New York, 1966.

(85) Molloy, K. C. Octahedral Complexes. In Group Theory for Chemists, 2nd ed.; Molloy, K. C., Ed.; Woodhead Publishing, 2013; Chapter 9, pp 97-108.

(86) Jorgersen, C. K. Absorption Spectra and Chemical Bonding in Complexes; Pergamon Press, 1962.

(87) Brisdon, B. J.; Lester, T. E.; Walton, R. A. Complex halides of transition metals-III electronic absorption spectra of 
hexahalotitanates(IV), vanadates(IV), and zirconates(IV). Spectrochim. Acta, Part A 1967, 23, 1969-1976.

(88) Signorile, M.; Crocellà, V.; Damin, A.; Rossi, B.; Lamberti, C.; Bonino, F.; Bordiga, S. Effect of Ti Speciation on Catalytic Performance of TS-1 in the Hydrogen Peroxide to Propylene Oxide Reaction. J. Phys. Chem. C 2018, 122, 9021-9034.

(89) Blasco, T.; Camblor, M. A.; Corma, A.; Perez-Pariente, J. The state of $\mathrm{Ti}$ in titanoaluminosilicates isomorphous with zeolite.beta. J. Am. Chem. Soc. 1993, 115, 11806-11813.

(90) Guo, Q.; Sun, K.; Feng, Z.; Li, G.; Guo, M.; Fan, F.; Li, C. A Thorough Investigation of the Active Titanium Species in TS-1 Zeolite by In Situ UV Resonance Raman Spectroscopy. Chem. - Eur. J. 2012, 18, 13854-13860.

(91) Zuo, Y.; Liu, M.; Zhang, T.; Hong, L.; Guo, X.; Song, C.; Chen, Y.; Zhu, P.; Jaye, C.; Fischer, D. Role of pentahedrally coordinated titanium in titanium silicalite-1 in propene epoxidation. RSC Adv. 2015, 5, 17897-17904.

(92) Maurelli, S.; Vishnuvarthan, M.; Chiesa, M.; Berlier, G.; Van Doorslaer, S. Elucidating the Nature and Reactivity of $\mathrm{Ti}$ Ions Incorporated in the Framework of AlPO-5 Molecular Sieves. New Evidence from 31P HYSCORE Spectroscopy. J. Am. Chem. Soc. 2011, 133, 7340-7343.

(93) de Groot, F. M. F.; Fuggle, J. C.; Thole, B. T.; Sawatzky, G. A. $2 \mathrm{p}$ x-ray absorption of $3 \mathrm{~d}$ transition-metal compounds: An atomic multiplet description including the crystal field. Phys. Rev. B 1990, 42, $5459-5468$.

(94) De Groot, F. M. F.; Fuggle, J. C.; Thole, B. T.; Sawatzky, G. A. L2,3 x-ray-absorption edges of d0 compounds: $\mathrm{K}+, \mathrm{Ca} 2+, \mathrm{Sc} 3+$, and Ti4+ in Oh (octahedral) symmetry. Phys. Rev. B 1990, 41, 928-937.

(95) Leapman, R. D.; Grunes, L. A.; Fejes, P. L. Study of the L23 edges in the $3 \mathrm{~d}$ transition metals and their oxides by electron-energyloss spectroscopy with comparisons to theory. Phys. Rev. B 1982, 26, 614-635.

(96) Note that NEXAFS spectroscopy is not sensitive to the nonequivalence of the $\mathrm{Cl}$ centered molecular orbitals (pointed out by $\mathrm{UV}$-vis spectroscopy), but it gives a deeper insight on the $\mathrm{Ti}(\mathrm{deg})$ orbitals, whose transitions were almost out of the spectral range explored by UV-vis spectroscopy.

(97) Zhao, X.; Zhang, Y.; Song, Y.; Wei, G. XPS study of interaction of titanium species with different internal electron donors on $\mathrm{Z}-\mathrm{N}$ catalysts. Surf. Rev. Lett. 2007, 14, 951-955.

(98) Jorgensen, C. K. Halogen Chemistry; Academic Press: New York, 1967; Vol. 1.

(99) Jorgensen, C. K. Electron Transfer Spectra. Prog. Inorg. Chem. 1970, 12, 101-157.

(100) Lukens, W. W.; Smith, M. R.; Andersen, R. A. A $\pi$-Donor Spectrochemical Series for $\mathrm{X}$ in (Me5C5)2TiX, and $\beta$-Agostic Interactions in $\mathrm{X}=\mathrm{Et}$ and $\mathrm{N}(\mathrm{Me}) \mathrm{Ph}$. J. Am. Chem. Soc. 1996, 118, 1719-1728.

(101) Atkins, P.; Overton, T.; Rourke, J.; Weller, M.; Armstrong, F. Shriver and Atkins' Inorganic Chemistry, 5th ed.; Oxford University Press: New York, 2010; p 824.

(102) Clark, R. J. H. Diffuse Reflectance Spectra of Some Anhydrous Transition-Metal Halides. J. Chem. Soc. 1964, 417-425.

(103) Baldini, G.; Pollini, I.; Spinolo, G. Optical Properties of $\alpha$ - and $\beta$-TiCl3. Phys. Status Solidi B 1968, 27, 95-100.

(104) Pollini, I. Electronic transitions in alpha and beta titanium trichloride. Solid State Commun. 1983, 47, 403-408.

(105) Stoyanov, E.; Langenhorst, F.; Steinle-Neumann, G. The effect of valence state and site geometry on $\mathrm{Ti}$ L3,2 and $\mathrm{O} \mathrm{K}$ electron energy-loss spectra of TixOy phases. Am. Mineral. 2007, 92, 577-586.

(106) Henderson, G. S.; Liu, X.; Fleet, M. E. A Ti L-edge X-ray absorption study of Ti-silicate glasses. Phys. Chem. Miner. 2002, 29, $32-42$.

(107) Martino, G. A.; Barzan, C.; Piovano, A.; Budnyk, A.; Groppo, E. Tracking the reasons for the peculiarity of $\mathrm{Cr} / \mathrm{Al} 2 \mathrm{O} 3$ catalyst in ethylene polymerization. J. Catal. 2018, 357, 206-212.

(108) Allouche, F.; Klose, D.; Gordon, C. P.; Ashuiev, A.; Wörle, M.; Kalendra, V.; Mougel, V.; Copéret, C.; Jeschke, G. Low-Coordinated
Titanium(III) Alkyl-Molecular and Surface-Complexes: Detailed Structure from Advanced EPR Spectroscopy. Angew. Chem., Int. Ed. 2018, 57, 14533-14537.

(109) Ashuiev, A.; Allouche, F.; Wili, N.; Searles, K.; Klose, D.; Copéret, C.; Jeschke, G. Molecular and supported Ti(iii)-alkyls: efficient ethylene polymerization driven by the $\pi$-character of metalcarbon bonds and back donation from a singly occupied molecular orbital. Chem. Sci. 2021, 12, 780-792.

(110) Morra, E.; Giamello, E.; Van Doorslaer, S.; Antinucci, G.; D'Amore, M.; Busico, V.; Chiesa, M. Probing the coordinative unsaturation and local environment of Ti3 + sites in an activated highyield Ziegler-Natta catalyst. Angew. Chem., Int. Ed. 2015, 54, 48574860.

(111) Ashuiev, A.; Humbert, M.; Gajan, D.; Norsic, S.; Blahut, J.; Searles, K.; Klose, D.; Lesage, A.; Pintacuda, G.; Raynaud, J.; Monteil, V.; Copéret, C.; Jeschke, G. Spectroscopic Signature and Structure of Active Centers in Ziegler-Natta Polymerization Catalysts revealed by Electron Paramagnetic Resonance. ChemRxiv 2020, No. 54777. 